\title{
A Dual Comparative Approach: Integrating Lines of Evidence from Human Evolutionary Neuroanatomy and Neurodevelopmental Disorders
}

\author{
Kari L. Hanson ${ }^{a}$ Branka Hrvoj-Mihic ${ }^{a}$ Katerina Semendeferi ${ }^{a, b}$ \\ a Department of Anthropology and ${ }^{\mathrm{b}}$ Neuroscience Graduate Program, University of California, \\ San Diego, La Jolla, Calif., USA
}

\section{Key Words}

Human brain evolution . Primate brain evolution .

Pyramidal neurons · Interneurons · Neurodevelopmental disorders - Williams syndrome

\begin{abstract}
The evolution of the human brain has been marked by a nearly 3 -fold increase in size since our divergence from the last common ancestor shared with chimpanzees and bonobos. Despite increased interest in comparative neuroanatomy and phylogenetic methods, relatively little is known regarding the effects that this enlargement has had on its internal organization, and how certain areas of the brain have differentially expanded over evolutionary time. Analyses of the microstructure of several regions of the human cortex and subcortical structures have demonstrated subtle changes at the cellular and molecular level, suggesting that the human brain is more than simply a 'scaled-up' primate brain. Ongoing research in comparative neuroanatomy has much to offer regarding our understanding of human brain evolution. Through analysis of the neuroanatomical phenotype at the level of reorganization in cytoarchitecture and cellular morphology, new data continue to highlight changes in cell
\end{abstract}

density and organization associated with volumetric changes in discrete regions. An understanding of the functional significance of variation in neural circuitry can further be approached through studies of atypical human development. Many neurodevelopmental disorders cause disruption in systems associated with uniquely human features of cognition, including language and social cognition. Understanding the genetic and developmental mechanisms that underlie variation in the human cognitive phenotype can help to clarify the functional significance of interspecific variation. By uniting approaches from comparative neuroanatomy and neuropathology, insights can be gained that clarify trends in human evolution. Here, we explore these lines of evidence and their significance for understanding functional variation between species as well as within neuropathological variation in the human brain. $\quad 2014$ S. Karger AG, Basel

\section{Introduction}

For primates, as particularly social mammals, the complexity of the social environment has been suggested as a principal driving force in the evolution of advanced cog-

\section{KARGER}

E-Mail karger@karger.com

www.karger.com/bbe
(C) 2014 S. Karger AG, Basel

0006-8977/14/0842-0135\$39.50/0
Dr. Katerina Semendeferi

Department of Anthropology, University of California, San Diego 9500 Gilman Drive 0532

La Jolla, CA 92093-0532 (USA)

E-Mail ksemende@ucsd.edu 
nitive faculties [Humphrey, 1976; Byrne and Whiten, 1989; Dunbar, 1998], encouraging the evolution of increased size and greater complexity in brain areas associated with social cognition, and the understanding of interindividual relationships among conspecifics. The challenges that a dynamic and hierarchical social environment present have fostered the development of advanced capacities for behavioral flexibility [Strier, 2006], inhibitory control of behavior [Amici et al., 2008] and associative learning [Haber et al., 2006; Williams et al., 2006] across primate lineages. Precipitous gains in object-focused intelligence and tool use [Byrne, 2004; Whiten and van Schaik, 2007], as well as language use [Tomasello et al., 1997; Deacon, 1997], and increased capacity for social learning through imitation [Call and Tomasello, 1995; Subiaul, 2007] and theory of mind [Povinelli and Eddy, 1996; Hare, 2007] have further characterized uniquely human features of human cognition and behavior.

By utilizing a comparative approach, we can better understand the differences in the brain's anatomy that underlie these key cognitive specializations. In addition to overall changes in brain size [Falk et al., 2000; Holloway, 2004] and the expansion of the cerebral cortex [Rilling and Insel, 1999], volumetric studies at the gross level have shown modifications that suggest reorganization in certain regions of the human brain [Barton and Harvey, 2000; Aldridge, 2011]. While humans and apes share a large frontal cortex [Semendeferi et al., 2002; Bush and Allman, 2004; Barton and Venditti, 2013], volumetric differences in certain areas suggest reorganization in areas of the prefrontal cortex [Semendeferi et al., 2001; Smaers, 2013; Passingham and Smaers, 2014]. Reduction in the size of the primary visual cortex [Holloway et al., 2003], coupled with the expansion of nearby parietal cortices [Bruner, 2010], additionally seem to suggest a trade-off in the relative sizes of these regions. Furthermore, major bilateral expansion of the temporal lobes has been observed [Semendeferi and Damasio, 2000; Rilling and Seligman, 2002]. Increases in white matter volume have been noted in areas of the prefrontal cortex [Smaers et al., 2010; but see also Sherwood et al., 2005] and broadly in the gyral regions of the cortex as compared to the core [Schenker et al., 2005], suggesting important differences in local connectivity among cortical regions. With regard to long-range connectivity among regions, increases in fractional anisotropy have been noted in the arcuate fasciculus [Rilling et al., 2008, 2011], associated with an increased density of fiber tracts connecting areas involved in language use and production, along with important differences in fiber terminations in expanded association territories. Associations between frontal white matter volume and basal ganglia volume further show evidence for humanspecific increases in frontostriatal connectivity underlying key differences in executive control [Smaers et al., 2010].

Differences in volume and connectivity in functional areas are likely reflected in subtle yet important changes at the level of cellular organization. Indeed, differences in cytoarchitecture have been observed in certain areas of the prefrontal cortex, including increased neuropil spacing in human frontopolar (Brodmann's area; BA 10) and frontoinsular cortices as compared to chimpanzees [Spocter et al., 2012]. Increased spacing between cortical minicolumns in the human frontal pole [Semendeferi et al., 2011] provides further evidence for reorganization in this region, suggesting differences in cellular organization and morphology related to its relative increase in size [Semendeferi et al., 2001]. These species differences in BA 10 in adults seem to reflect important changes in development: whereas horizontal spacing distance between cortical minicolumns increased with age pre- versus postweaning in human subjects, similar increases were not observed in chimpanzees [Teffer et al., 2013]. Increased dendritic branching of pyramidal neurons in BA 10 [Bianchi et al., 2013] seems to correlate with this trend toward increased space, presumably to accommodate increased connections between cells. Wider minicolumn spacing in development may necessarily correspond to expanded surface area [Rakic and Kornack, 2001]. Indeed, differences in white matter density seem to reflect regionally specific differences in connectivity [Schenker et al., 2005], and disruption in cortical layering patterns is also reflected in gyral convolutions [van Essen, 1997; Hilgetag and Barbas, 2006]. Therefore, differences observed at the level of individual cortical layers and neurons across several primate species can provide insights into evolutionary changes underlying gross anatomical variation across taxa.

Increasingly, studies targeting neurodevelopmental disorders characterized by perturbations of gross morphology of the brain also find differences in its intrinsic microstructure. For example, narrower minicolumn spacing has been noted in the prefrontal cortex of individuals with autism [Casanova et al., 2002, 2006; Buxhoeveden et al., 2006], which may contribute to selective deficits in the executive function and social engagement characteristic of the disorder. A developmental shift to 
wider minicolumn spacing in the frontal pole postweaning is a feature of human, but not chimpanzee cortical development [Teffer et al., 2013]. We can therefore expect that this important developmental event affects cellular morphology in a way that, in turn, influences cellular function, affecting important features of cognition and behavior that are impaired in autism [Courchesne et al., 2011]. Thus, variation in development observed within the human species could be of significance for understanding the functional implications of differences in cognition between species.

Uniting approaches from the study of neurodevelopmental disorders and comparative evolutionary neuroanatomy offers powerful tools for understanding the genetic, developmental and neuroanatomical influences on the human cognitive and behavioral phenotype. Here, we will discuss variation in cortical and subcortical microstructure both between hominoid species (i.e. apes and humans), and among pathological variations in the human neuroanatomical phenotype, drawing parallels in morphology and function to elucidate mechanisms that underlie inter- and intraspecific variability in cognition and behavior. Some neurodevelopmental disorders may provide better models than others for understanding functional implications of neurodevelopmental abnormalities, such as autism and schizophrenia, due to their specific influences on uniquely derived human cognitive traits and social behaviors. Given its well-characterized genetic etiology and consistent social and cognitive phenotype, we will further argue that Williams syndrome can provide an ideal model for understanding variation in the human neuroanatomical phenotype underlying important behavioral specializations.

\section{Pyramidal Neurons: Morphology, Functional Considerations and Evolutionary Importance}

Focus on specific neuronal subtypes offers possibilities for more detailed insights into the processing capabilities of a particular cortical area or a specific cortical layer, and their variation in homologous areas across taxa. Ultimately, this focus elucidates our understanding of genetic mechanisms underlying the observed morphological variations. This allows for analyses of evolutionary scenarios directed specifically at neurons as information-processing units, their organization and morphology as indicative of the nature of the networks they form, and variation reflecting selective pressures favor-

Human Evolutionary Neuroanatomy and Neurodevelopmental Disorders ing a particular type of cortical organization in a taxon. In the cortex of mammals, pyramidal neurons represent the main morphological class of neurons, accounting for $70-85 \%$ of all cortical neurons [DeFelipe and Fariñas, 1992]. Pyramidal neurons form basic units of cortical microcircuitry, determining the pattern of information flow within a particular cortical area or a cortical layer [DeFelipe et al., 2002]. Although variation in functional properties of pyramidal neurons does exist [e.g. Chagnac-Amitai et al., 1990; Connors and Gutnick, 1990; Mainen and Sejnowski, 1996], they are nevertheless unified by their morphology. They are typically characterized by a pyramidal- or ovoid-shaped soma, one apical dendrite directed toward the pial surface, several basal dendrites emerging from the sides of the soma, a single axon emerging from the soma or proximal parts of basal dendrites, and the presence of spines representing excitatory inputs onto dendritic surfaces (fig. 1) [DeFelipe and Fariñas, 1992; Nieuwenhuys, 1994; Spruston, 2008].

Across species, pyramidal neurons vary in the length of dendrites and branching complexity, and in the number and density of dendritic spines [Cupp and Uemura, 1980; Jacobs et al., 1997; Elston and Rosa, 2000; Elston et al., 2001; Jacobs et al., 2001; Elston et al., 2005a; Elston, 2007; Bianchi et al., 2012]. Within the cortex of primate species examined to date - notably macaques, chimpanzees and humans - pyramidal neurons vary across functionally distinct cortical areas, displaying less elaborated dendritic arbors in primary and unimodal areas (e.g. BA 4, BA 3-1-2) and more complex arbors and a higher number of spines in association areas, such as the prefrontal cortex [Cupp and Uemura, 1980; Jacobs et al., 1997, 2001; Elston, 2007; Bianchi et al., 2012]. In addition, pyramidal neurons represent sites of plasticity in the cortex, and their modifications have been reported in various mammalian species, both in developing and in already established networks, as a response to numerous environmental manipulations [Bryan and Riesen, 1989; Cook and Wellman, 2004]. In humans, modifications occur in several cognitive disorders, including, among others, autism spectrum disorder (ASD), Rett syndrome (RTT), Down syndrome, and schizophrenia [Marin-Padilla, 1972, 1976; Belichenko et al., 1994a; Garey et al., 1998; Glantz and Lewis, 2000; Hutsler and Zhang, 2010].

Prior or in parallel to expanding the analysis of pyramidal neurons from an evolutionary perspective, two concepts deserve further consideration. These are, first, a potential uniqueness of pyramidal neurons in humans, in particular morphological changes compared to those ob- 
Fig. 1. Schematic representation of a pyramidal neuron in the human visual cortex. Dots represent dendritic spines.

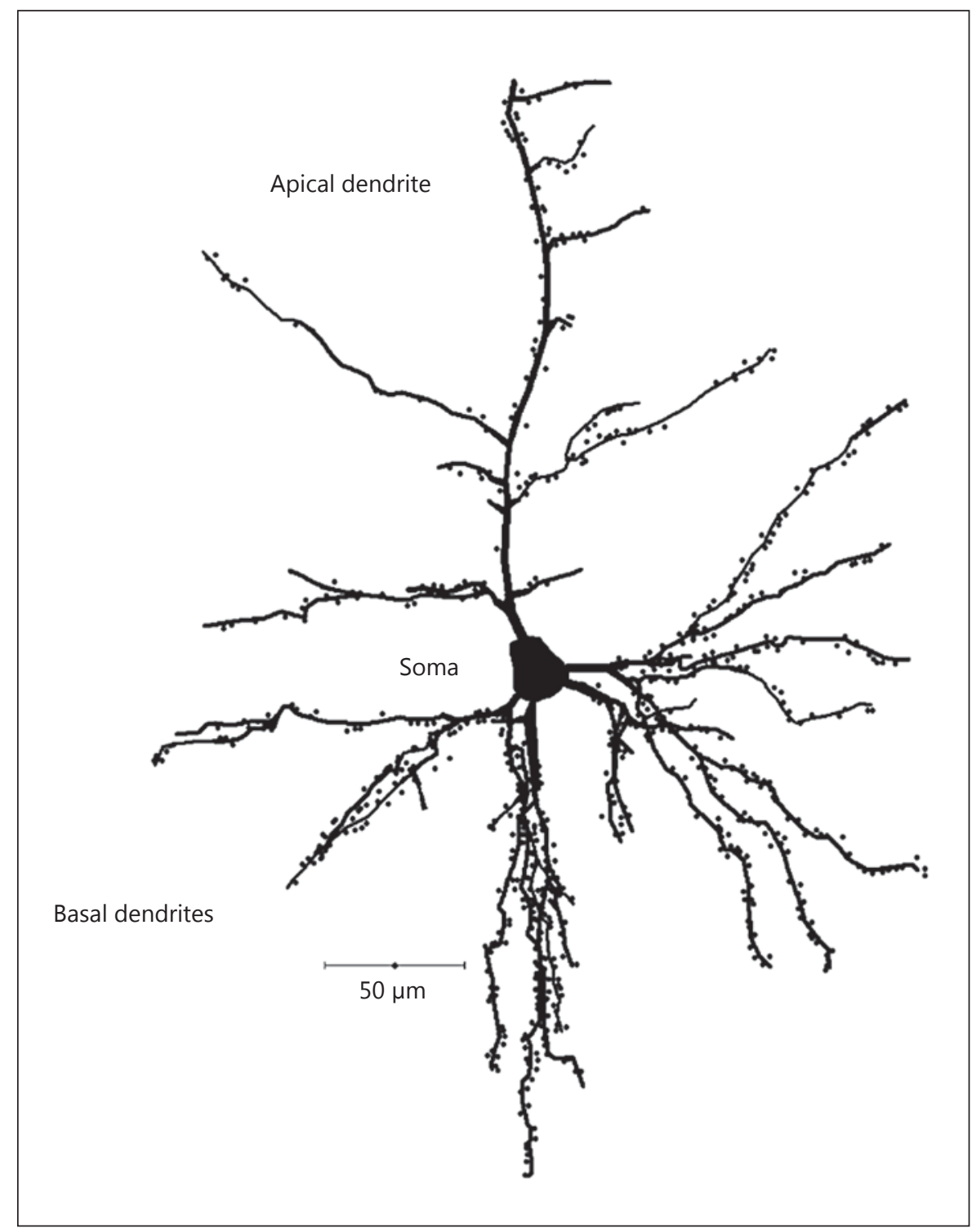

served in other mammalian species in response to the same set of environmental inputs and, second, the functional aspects behind neuronal morphology that can be inferred from aberrations in neuronal morphology in cognitive disorders with specific behavioral profiles compared to unaffected individuals. These concepts highlight the need for studies examining the morphology of the neurons across different species of primates in a manner that would allow for comparisons across studies. To date, very few primate species have been examined in this way (table 1), and expanding comparative studies across mammals and in human neurological disorders can enhance previous findings.

\section{Pyramidal Neurons in Mammals: Morphological Variation across Species}

An important feature of pyramidal neurons in primates is the difference in morphological complexity across functionally distinct cortical areas and cortical layers [Jacobs et al., 1997; Elston and Rosa, 2000; Elston et al., 2001; Jacobs et al., 2001; Elston et al., 2006; Petanjek et al., 2008; Bianchi et al., 2012], with neurons displaying more complex dendritic branching and greater numbers of synaptic inputs located in association cortices compared to those of unimodal cortical areas. Interestingly, even within the same level of func- 
Table 1. List of studies analyzing the morphology of pyramidal neurons in different species of non-human primates

\begin{tabular}{|c|c|c|c|}
\hline Species & Cortical area & Age & Reference \\
\hline $\begin{array}{l}\text { Chimpanzee } \\
\text { (Pan troglodytes) }\end{array}$ & $\begin{array}{l}\text { PFC (BA 10) } \\
\text { sensory cortex (BA 3) } \\
\text { motor cortex (BA 4) } \\
\text { visual cortex (BA 18) }\end{array}$ & newborn to 9 years; adult & $\begin{array}{l}\text { Bianchi et al., 2012 } \\
\text { Bianchi et al., } 2013^{\mathrm{b}}\end{array}$ \\
\hline $\begin{array}{l}\text { Rhesus macaque } \\
\text { (Macaca mulatta) }\end{array}$ & $\begin{array}{l}\text { PFC } \\
\text { frontal (BA 6, BA 4) } \\
\text { cingulate cortex (BA 24, BA 23) } \\
\text { parietal (BA 3, BA 5; BA 7) } \\
\text { temporal cortex (IT) } \\
\text { occipital cortex (BA 17) }\end{array}$ & $\begin{array}{l}7-28 \text { years }(\mathrm{PFC}) \text {; adults } \\
\text { of unspecified age for the } \\
\text { remaining areas }\end{array}$ & $\begin{array}{l}\text { Cupp and Uemura, } 1980^{\mathrm{b}} \text {; } \\
\text { Elston and Rockland, 2002; } \\
\text { Elston et al., 2005a }\end{array}$ \\
\hline $\begin{array}{l}\text { Long-tailed macaque } \\
\text { (Macaca fascicularis) }\end{array}$ & $\begin{array}{l}\text { PFC (BA 10) } \\
\text { cingulate cortex (BA 24, BA 23) } \\
\text { temporal cortex (TEO, TE, STP; } \\
\text { auditory area A1) } \\
\text { occipital cortex (BA 17, BA 18) } \\
\text { comparative analysis of visual } \\
\text { processing areas (V1, V2, V3, TEO) }\end{array}$ & $\begin{array}{l}18 \text { months; adult } \\
\text { (2 PND to } 4.5 \text { years for } A 1 \text {; } \\
14-28 \text { months for visual } \\
\text { areas) }\end{array}$ & $\begin{array}{l}\text { Elston and Rosa, 1998, 2000; } \\
\text { Elston et al., 2001 }{ }^{\mathrm{a}}, 2005 \mathrm{a} \text {, } \\
2006^{\mathrm{a}}\end{array}$ \\
\hline $\begin{array}{l}\text { Macaque (species } \\
\text { not defined) }\end{array}$ & PFC (BA 10, BA 11, BA 12) & 12 years & Elston, 2000 \\
\hline $\begin{array}{l}\text { Chacma baboon } \\
\text { (Papio ursinus) }\end{array}$ & $\begin{array}{l}\text { PFC } \\
\text { frontal (BA 6, BA 4) } \\
\text { cingulate cortex (BA 24, BA 23) } \\
\text { occipital cortex (BA 17, BA 18) } \\
\text { parietal (BA 3, BA 5; BA 7) } \\
\text { comparative analysis of visual } \\
\text { processing areas (V1, V2, V4) }\end{array}$ & adult & $\begin{array}{l}\text { Elston et al., 2005b, c, da, } \\
2006^{\mathrm{a}}\end{array}$ \\
\hline $\begin{array}{l}\text { Owl monkey } \\
\text { (Aotus trivirgatus) }\end{array}$ & $\begin{array}{l}\text { PFC (BA 10) } \\
\text { occipital cortex (BA 17, BA 18) }\end{array}$ & adult & Elston et al., 2006 \\
\hline $\begin{array}{l}\text { Galago } \\
\text { (Otolemur garnetti) }\end{array}$ & $\begin{array}{l}\text { PFC (BA 10) } \\
\text { occipital cortex (BA 17, BA 18) } \\
\text { comparative analysis of visual } \\
\text { processing areas (V1, V2, V4, IT) }\end{array}$ & adult & Elston et al., $2005 \mathrm{~h}^{\mathrm{a}}, 2006^{\mathrm{a}}$ \\
\hline
\end{tabular}

PFC $=$ Prefrontal cortex; PND = postnatal days.

${ }^{a}$ Studies comparing the morphology of neurons across species. ${ }^{b}$ Studies using the rapid Golgi method for visualization of neuronal morphology; the remaining studies used Lucifer yellow injections.

Human Evolutionary Neuroanatomy and Neurodevelopmental Disorders 
tional hierarchy, and within the same macroscopically defined area, pyramidal neurons can differ in their morphological complexity. In the human cortex, for example, although pyramidal cells in upper layer III in both BA 10 and BA 11 of the prefrontal cortex display more elaborated arborizations and a higher number of spines than those in low integration areas, BA 11 neurons are typically less complex than BA 10 neurons, being the least complex among the neurons in high integration areas [Jacobs et al., 2001]. Although BA 10 and BA 11 differ cytoarchitectonically, in their connectivity, and presumably in function [Barbas et al., 1991; Barbas, 1995], both form part of the prefrontal cortex, an integration area implicated in a number of complex cognitive tasks. While BA 10 underwent an increase in size [Semendeferi et al., 2001] and changes in its organization [Semendeferi et al., 2011] during the course of human evolution, the evolutionary trajectory of BA 11 is currently unknown. It remains to be explored whether the two areas solved the need for complex processing differently, with one area increasing the space available for neuronal connectivity, allowing for greater complexity of pyramidal arbors, and the other possibly favoring less elaborated but more densely packed neurons [Schlaug et al., 1993; Barbas and Hilgetag, 2002]. This possibility was also proposed by Zeba et al. [2008] in their analysis of lower layer III neurons in the prefrontal cortex (BA 9), Broca's area (BA 45), and primary motor cortex (BA 4) in humans. Unlike their upper layer counterparts, large pyramidal neurons in lower layer III did not display differences in length, branching complexity, or in the number or distribution of dendritic spines across the three functionally distinct areas. Instead, the authors noted that these areas differed in the density of long-distance-projecting neurons labeled with SMI-32 antibody against nonphosphorylated epitopes of neurofilament protein. The highest density of SMI-32-positive neurons was reported in BA 9, followed by Broca's area and BA 4. In BA 4, the majority of long-projecting neurons were located in layer $\mathrm{V}$, whereas, in the other two areas, SMI-32-positive neurons were found in lower layer III. Zeba et al. [2008] proposed that instead of increasing complexity of dendritic arbors in individual neurons, the need for functional complexity might have been served by increasing the ratio of the most complex neurons. This hypothesis raises additional possibilities to test the interplay between the structure and function of pyramidal neurons on one hand, and the processing demands of a particular cortical area on the other.
Analyses of postmortem tissue suggest that different aspects of dendritic morphology emerge and stabilize at different ages, and current research, although based on a small sample of primate species, suggests that humans display a delay in the maturation of pyramidal neurons compared to other primates [Petanjek et al., 2008, 2011; Bianchi et al., 2013]. Dendrites of pyramidal neurons in the developing chimpanzee prefrontal cortex (BA 10) remain shorter and less spinous compared to primary processing areas (BA 3, BA 4) throughout infancy and the juvenile period, and increase in their complexity after the age of 9 years [Bianchi et al., 2013]. In comparison, although the main period of dendritic development in the human prefrontal cortex (BA 9) is centered around the first few postnatal years, further growth of dendritic trees in prefrontal cortex pyramidal neurons continues throughout childhood and adolescence [Petanjek et al., 2008]. As developing neurons are more plastic than neurons in mature networks, the developmental delay observed in humans may underlie delayed cognitive maturation. This prolonged period of neuronal development potentially allows additional time for learning skills and behaviors needed to navigate a complex social environment, and the acquisition of cultural tools necessary for successful survival. Although large-scale changes in the morphology of dendritic trees tend to diminish with age, smaller changes continue to occur throughout life, thus providing life-long plasticity in the cortex.

Dendritic modifications in response to environmental influences, as well as chemical and behavioral manipulations, have been reported across mammals of various ages [Volkmar and Greenough, 1972; Globus et al., 1973; Uylings et al., 1978; Greenough et al., 1979; Bryan and Riesen, 1989; Cook and Wellman, 2004; Brown et al., 2005], with pyramidal neurons responding by modifying different aspects of their morphology, depending on the cortical area and laminar location. Most importantly, the effects appear to vary depending on the age of animals and across species, and the same type of stressor does not necessarily invoke the same - or even similar - modifications of pyramidal neurons in the human as in the rodent cortex (table 2; see in particular the discussion about neuronal modifications following callosotomy in humans as compared to rabbits below). Studies in rats, for example, have suggested that apical dendrites appear more prone to changes in response to both acute and chronic stress as compared to basal dendrites [Cook and Wellman, 2004; Brown et al., 2005]. Reductions in apical dendrites were noted in the total length and number of branches, especially the number of terminal branches in layer II/III py- 
Table 2. List of selected experiments reflecting modification in the morphology of cortical pyramidal neurons in response to environmental manipulation

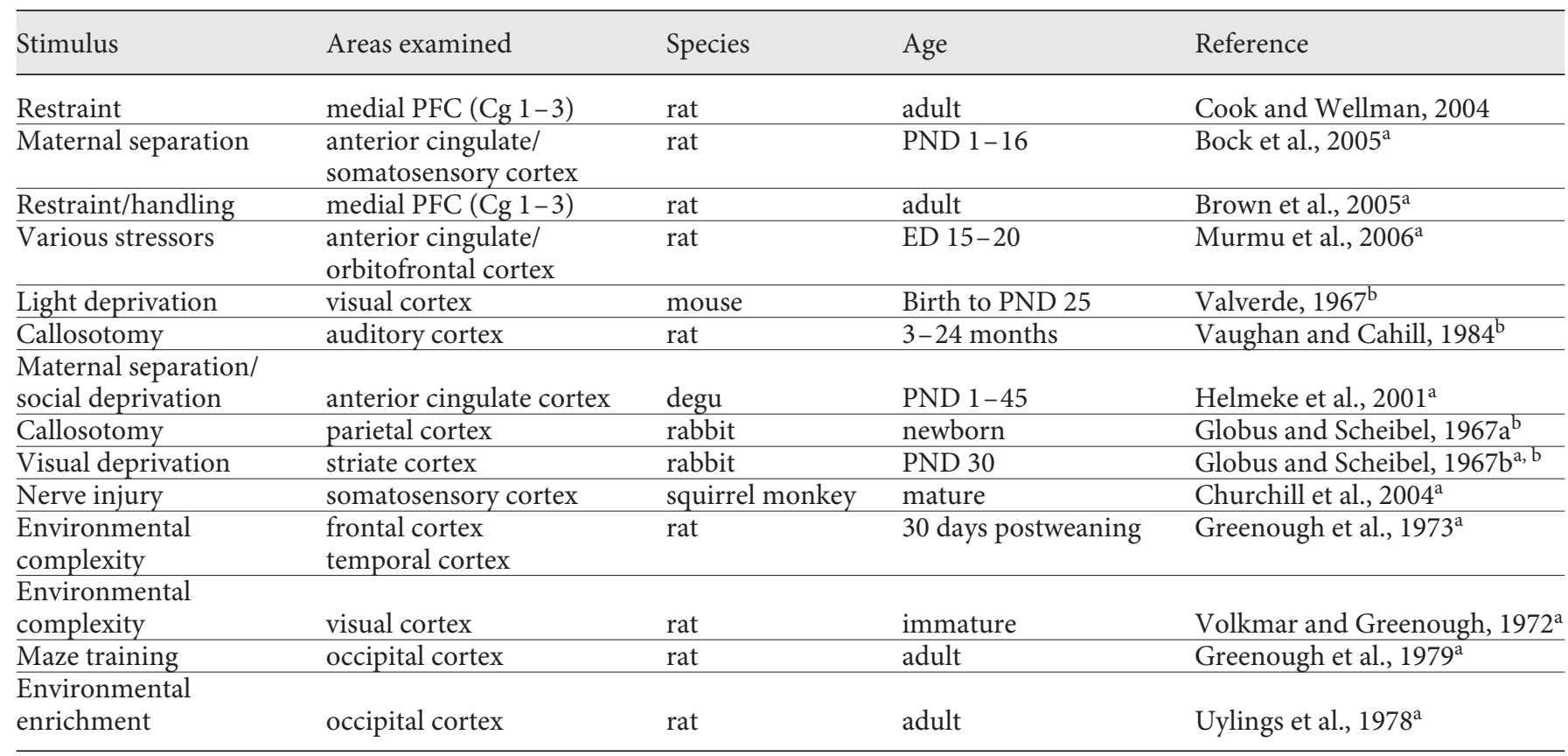

$\mathrm{ED}=$ Embryonic day; $\mathrm{PND}=$ postnatal day; $\mathrm{PFC}=$ prefrontal cortex.

a Studies utilizing modifications of the Golgi-Cox technique.

${ }^{\mathrm{b}}$ Studies utilizing various modifications of the rapid Golgi technique.

ramidal neurons in the rostral cortex, while the morphology of basal dendrites remained unaffected. Interestingly, neither the density nor morphology of spines changed in response to acute stress in mature animals [Cerqueira et al., 2007], whereas, in developing pups, the effects varied depending on the animal's age.

In rats born to mothers exposed to stress during pregnancy, the density of spines was reported to have decreased along apical dendrites of pyramidal neurons in the anterior cingulate cortex, whereas spines on basal dendrites did not appear affected. In the orbitofrontal cortex, spine density changed in both basal and apical dendrites, and the length of apical dendrites decreased in both cortical regions. The middle dendritic segments were mostly affected in the orbitofrontal and distal segments in the anterior cingulate cortex [Murmu et al., 2006]. Exposure to stress during the first 3 postnatal days resulted in a decreased density of spines on basal and apical dendrites in the anterior cingulate, and a decreased length of apical dendrites. The same condition resulted in an increased density of spines on basal dendrites and their elongation in 2-week-old rats, while apical den- drites did not exhibit any change in response to stress during the same developmental period [Bock et al., 2005]. At the same time, the density of spines increased in the primary somatosensory cortex, regardless of the age of the animals [Bock et al., 2005]. Similar findings were reported in the degu (Octodon degus), where deprivation during the first 3 postnatal weeks resulted in longer and more spinous apical dendrites, but no change in the length of dendrites if the pups were removed from their mothers and siblings after weaning [Helmeke et al., 2001].

Reports suggest that positive experiences similarly influence the morphology of pyramidal neurons, with the effects again differing between cortical areas and cortical layers. Exposure to an enriched environment, for example, is associated with an increased density of spines on basal dendrites [Globus et al., 1973], as well as with increased basal dendritic branching and increased length of terminal dendritic segments on neurons in the occipital cortex of rodents [Uylings et al., 1978]. An increase in dendritic complexity is also associated with exposure to maze training, with the effects again mostly localized to 
distal segments, in this case of apical dendrites [Greenough et al., 1979]. Higher-order dendritic branching appears more elaborated in the occipital cortex [Volkmar and Greenough, 1972] and branching complexity of basal dendrites in the temporal cortex [Greenough et al., 1973] of rats reared in a complex environment. Different rearing conditions appear not to influence the morphology of pyramidal neurons in the rodent frontal cortex [Greenough et al., 1973], which raises an important issue given the integrative role of prefrontal regions in primates and the robustness of certain morphological features of BA 10 neurons in older human subjects [Jacobs et al., 1997].

Taken together, rodent studies support the notion that environmental influences are capable of promoting remodeling of pyramidal neurons, and that these effects differ across functionally and hierarchically different cortical areas, and vary with respect to the age of the animals. Studies employing a similar experimental design cannot be performed in humans and most non-human primates (but see Jacobs et al. [1993] for the possible influence of formal education on dendritic complexity). However, before extrapolating from rodent studies about environmental effects on the morphology of neurons in the cortex of primates, it remains to be determined whether pyramidal neurons in different species respond to the same stimuli differently, depending on the connectivity of a particular area and laminar location of the neurons.

A comparison of morphological changes in the human and rabbit cortex following callosotomy suggests that, indeed, the modifications in the morphology of pyramidal neurons differ in humans compared to other animals. In the cortex of patients who underwent treatment for seizures, Jacobs et al. [2003] reported the presence of pyramidal neurons in layer III with unusually long, branched and spinous basal dendrites that descend deep into subgranular layers. These dendrites were particularly common in Broca's area [Jacobs et al., 2003], that is, the area losing numerous interhemispheric connections following callosotomy from its homologue in the right hemisphere and from the right inferior temporal cortex [Di Virgilio and Clarke, 1997]. The abnormal basilar dendrites, as the authors suggested, possibly represent an attempt of the neurons to maintain their function after losing cross-callosal inputs by increasing the area available for connections within the same hemisphere. Interestingly, Jacobs et al. [2003] also noted that spine loss, typical of epileptic tissue, was not present in the brains of patients several decades after seizures had ceased, suggesting again the ability of neurons to 'repair' their morphology after factors influencing their reorganization had disappeared. In contrast, callosotomy in rabbits resulted in a decrease in spine numbers on oblique branches of apical dendrites in the parietal cortex, with little change to the morphology of basal dendrites [Globus and Scheibel, 1967a]. Beyond the basic suggestion that the cortex of each species may respond differently to the same stressor (e.g. loss of cross-callosal connections) depending on the connectivity of a particular cortical area, it remains difficult to extend conclusions based on the limited number of studies. However, the existing data do suggest that attempts to discern the structure-function relationship based on the response observed in one species remain problematic, and should be approached with caution.

\section{Pyramidal Neurons in Humans: Insights from \\ Neurodevelopmental Disorders}

Anomalies in dendritic morphology have been reported in various cognitive disorders, in response to exposure to toxins, medications and injury, as well as in both normal aging and dementia (table 3 ). The morphology of pyramidal neurons in mental retardation and other cognitive disorders attracted attention during the 1970s with the studies of Huttenlocher [1970, 1974] and Purpura [1974] of the developing cortex in unspecified mental retardation cases, and the study of Marin-Padilla [1972] of the developing motor cortex in Down syndrome and Patau syndrome. During the 1970s and 1980s, morphometric analyses remained focused on the conditions with distinct behavioral phenotypes and a clear genetic component and, to date, pyramidal neurons in the conditions with chromosomal aberrations remain the most researched among neurodevelopmental disorders. Pyramidal neurons in neurodevelopmental disorders seem to display differences compared to control subjects, which may be specific to a particular disorder [Armstrong et al., 1998; but for similarities across different pathologies see also Kaufmann and Moser, 2000]. In addition, the effects on the organization of dendrites tend not to be equally distributed across functionally distinct cortical areas. Pyramidal cells are differently affected in specific areas, as well as within particular layers. Neurons in patients with ASD, for example, tend to display an increased density of spines compared to typical subjects of the same age [Hutsler and Zhang, 2010]. However, the pathologies are present in layer III across several cortical areas (BA 7, BA 9 and BA 21), whereas cortical layer $V$ appears affected in BA 21, with no changes between ASD subjects and controls observed in the other two areas [Hutsler and Zhang, 2010]. 
Table 3. List of all postmortem human studies in selected neurodevelopmental disorders with a focus on morphological changes of cortical pyramidal neurons

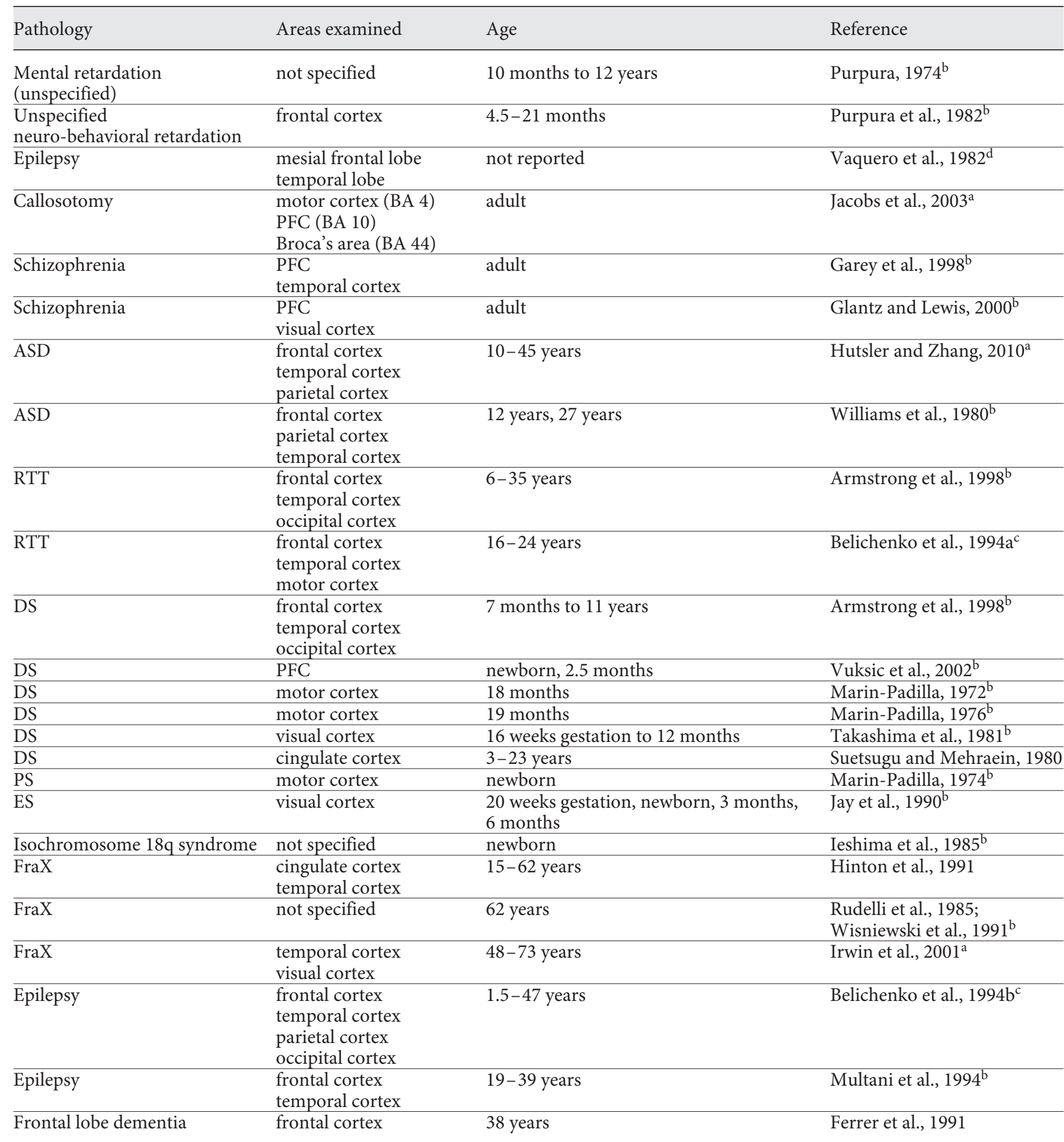

DS = Down syndrome; PS = Patau syndrome; ES = Edwards syndrome; FraX = fragile X syndrome; PFC = prefrontal cortex. ${ }^{\text {a Studies }}$ utilizing the Golgi-Kopsch technique. ${ }^{b}$ Studies utilizing various modifications of the rapid Golgi technique. ${ }^{c}$ Studies utilizing the Lucifer yellow technique. ${ }^{\mathrm{d}}$ Studies utilizing the Golgi Cox technique.

Human Evolutionary Neuroanatomy and Neurodevelopmental Disorders 
Of particular interest for evolutionary studies are disorders with impairments in specific aspects of social function. The ability to successfully navigate one's social environment has been proposed as an important pressure shaping the evolution of the human brain [Dunbar, 1998]. The behavioral phenotype, coupled with microstructural changes in these disorders, provides insights into the relationship between the organization of microcircuitry in areas subserving processing of social information and their behavioral correlates. In addition to the pathologies in the morphology and number of dendritic spines in autism discussed above, deficiencies in RTT, a disorder previously classified under ASD and characterized by a specific MECP2 mutation, display various other modifications. Variation across functionally different cortical areas, as seen in controls, are absent in RTT [Belichenko et al., 1994a]. In the prefrontal cortex (BA 10), supragranular layers (layers II/III) appear more affected than the infragranular layers (V/VI), whereas in BA 4 the effect is the opposite, with layers V/VI being more affected than layers II/III. Differences between RTT patients and controls appear equally distributed in both supra- and subgranular layers in Wernicke's area (BA 22). The number of spines, however, was consistently reduced across all cortical layers [Belichenko et al., 1994a]. Preliminary analyses have suggested that the typical variation in dendritic complexity of pyramidal neurons across functionally different cortical areas may also be compromised in Williams syndrome [Hrvoj-Mihic et al., 2013], a disorder displaying social and linguistic features in many respects opposite to that of ASD and RTT.

Application of the induced pluripotent stem cell (iPSC) technique, capable of reprogramming somatic tissue and potentially generating species-specific neuronal cells in vitro, opens the possibility to extend evolutionary analyses beyond morphological descriptions. The technique has been applied in the analysis of neural disorders - for example, neurons obtained from fibroblasts of RTT patients successfully replicated the morphology of pyramidal neurons and provided insights into functional characteristics, including analyses of the neuronal progenitor cell cycle, measurements of calcium transient activity, and postsynaptic currents associated with morphological modification. In addition to changes in morphology, reprogrammed RTT neurons displayed electrophysiological deficits and altered calcium signaling compared to controls [Marchetto et al, 2010]. The iPSC technique was also utilized in modeling disorders of multicausal origin, for exam- ple, schizophrenia [Brennard et al., 2011], and in Williams syndrome [Chailangkarn et al., 2013]. Neurons derived from reprogrammed cells replicated the morphology of neurons typical of the disorder, and additional analyses of the cells revealed functional differences between pathological and control neurons. The combination of the two different approaches - postmortem morphological analyses of cortical neurons and analyses of neurons using iPSCs - provides a fertile ground for evolutionary studies [Hrvoj-Mihic et al., 2014], and offers a possibility to surpass the limitations imposed upon comparative neuroanatomy in examining functional correlates of the observed morphological differences.

\section{Beyond Pyramidal Neurons: Inhibitory Interneurons in the Cortex}

While pyramidal neurons are the most ubiquitous neuron type in the cerebral cortex, a diverse array of interneuron subtypes act locally to modulate the activity of these pyramidal cells. In the primate cerebral cortex, approximately $15-30 \%$ of neurons are inhibitory, GABAergic interneurons [DeFelipe, 1997; Sherwood et al., 2010]. Inhibitory interneurons of the cerebral cortex serve an important role in modulating excitatory neuronal function, including control of rhythmic oscillations across assemblages of pyramidal neurons [DeFelipe, 1997] important for the regulation of spike-timing-dependent synaptic plasticity. GABAergic interneurons additionally regulate subcortical input to the cortex [Hendry et al., 1987; Porter et al., 2001].

In the cortex, the calcium-binding proteins calbindin (CB) D-28k, calretinin (CR), and parvalbumin (PV) colocalize with GABA in $90-95 \%$ of interneurons. These interneurons display a variety of morphological types, including PV-reactive chandelier and large basket cells, CBreactive double bouquet cells, CR-reactive bipolar double bouquet cells, and some Cajal-Retzius cells. The exact morphology and pattern of synaptic formation of each class of GABAergic inhibitory interneurons varies relative to the cortical region and layer in which it resides, but can be distinguished according to general patterns [Ascoli et al., 2008; DeFelipe et al., 2013]. Functionally distinct types of inhibitory interneurons, characterized by differences in immunohistochemical markers and postsynaptic morphology, owe their distinctive traits to differences in their origin and regulation during fetal development [Wonders and Anderson, 2006]. 
Maintaining the delicate balance between excitatory and inhibitory neuronal activity is essential for proper brain function. Many neurodevelopmental disorders have been shown to involve disruption in the balance between excitatory and inhibitory cortical neurons, as revealed through postmortem anatomical studies, and differential activity, as measured in vivo in animal models of these disorders [Marín, 2012]. Many of these disorders differentially affect certain cognitive faculties that are particular to the human behavioral phenotype, including language use and complex aspects of social cognition. Schizophrenia, for example, is a severe psychiatric disorder characterized by delusions and hallucinations, in addition to cognitive deficits in attention and working memory, as well as major deficits in social behavior and recognition of affect [Green and Horan, 2010]. Recent research has shown that schizophrenia's unique symptoms are the result of vulnerabilities associated with recent adaptive genomic changes associated with the human neurocognitive phenotype [Crow, 2000; Crespi et al., 2007; Khaitovich et al., 2008]. Specifically, the rapid evolution of certain traits, including linguistic capacity [Crow, 1998, 2000] and advanced aspects of social cognition, such as empathy and mentalizing [Brüne, 2005; Burns, 2006] and executive function, which are severely affected in schizophrenia, point to derived features of human neurobiology supporting these unique faculties. Cognitive effects of schizophrenia seem to point to the involvement of a breakdown in synchronization of gamma oscillations in the dorsolateral prefrontal cortex. These electrophysiological data implicate dysfunction in fast-spiking, PV-positive inhibitory interneurons, which are reportedly decreased in number [Benes, 1991]. More nuanced mechanisms are likely also involved: in PV-positive basket cells, decreased expression of GAD67, an enzyme associated with GABA transmission, underlies inefficacy in the inhibitory control of pyramidal neurons [Lewis et al., 2012]. A variety of other genes are likely involved in the dysfunction of PV-positive basket cells, and animal models of the disorder have highlighted the involvement of several promising candidate genes in their dysfunction [Marín, 2012].

ASD additionally affects aspects of social cognition that merit study in a comparative framework, and associated pathophysiologies point to the involvement of interneuron dysfunction in these disorders. Functional studies [Orekhova et al., 2007; Dinstein et al., 2011] have shown disruptions in oscillatory frequencies, particularly in response-inhibition tasks [Rubenstein and Merzenich, 2003; Yizhar et al., 2011] that implicate dysfunction in the

Human Evolutionary Neuroanatomy and Neurodevelopmental Disorders balance of inhibitory and excitatory neuronal activity. Reductions in GABAergic receptors in the anterior and posterior cingulate cortices, as well as the fusiform gyrus, have also been demonstrated in autism [Oblak et al., 2009, 2010, 2011]. Postmortem histological investigations have found reductions in the number of PV interneurons in the dorsolateral prefrontal cortex, specifically BA 9, in a small sample of autistic patients [Zikopoulos and Barbas, 2013]. Additionally, this study found that the overall ratio of $\mathrm{PV}$ versus $\mathrm{CB}$ interneurons showed a decrease by nearly one third, suggesting decreased inhibitory efficacy in local networks. A relative increase of PV interneuron ratios is a derived trait in the primate cortex, as compared to other mammalian species [Dombrowski, 2001]. This could have interesting implications for derived features of inhibitory control that underlie social cognition, such that cellular mechanisms contributing to inhibitory control of behavior could have been a target of selection, of particular importance for animals living in hierarchical social groups [Amici et al., 2008]. Many other cortical areas, including the fusiform face area, show evidence for disrupted synchrony between alpha and gamma oscillatory frequencies [Buard et al., 2013], which further implicate PV interneuron dysfunction. It is likely that the downstream effects of the decrease in PV interneurons in BA 9 are systemic in nature, and contribute to both local and global dysfunction in mechanisms of attention and cognition [Zikopoulos and Barbas, 2013].

Whereas multiple molecular and environmental mechanisms have been shown to contribute to autism and schizophrenia, other disorders with a more clear-cut genetic etiology show evidence for pathologies of interneuron function that affect social cognition. In fragile $\mathrm{X}$ syndrome, for example, a reduction in numbers of interneurons have been noted, as well as a reduction in numbers of GABA receptors, likely mediated by a global reduction in the expression of GAD65 and GAD67 [Mulle et al., 2007; Curia et al., 2009]. Similar mechanisms seem to underlie deficits in learning and memory in RTT, where decreased levels of cortical GABAergic transmission cause impairments in inhibitory function [Chao et al., 2010]. Further study of the associated perturbations of inhibitory function in disorders characterized by known genetic deletions will help to elucidate mechanisms of interneuronal function that underlie differences in cognition.

Studying the developmental and genetic mechanisms that underlie disorders affecting uniquely human aspects of cognition can provide an essential window into mechanisms guiding normal social and cognitive development 
and its evolution. Through comparative analyses, we can begin to further understand how the function of specialized cells contributes to interspecific variation in cognitive abilities. Previous research, however, has not found differences in inhibitory interneuron numbers or their distribution in cortical areas, including BA 9, BA 4, BA 32 and BA 44, between humans and anthropoid primates [Sherwood et al., 2010]. The conserved phenotype displayed by inhibitory interneurons in the cortex suggests instead that other genetic and regulatory mechanisms contribute to differences in functional regulation of pyramidal cells by inhibitory interneurons. These may be particularly vulnerable to the effects of cognitive dysfunction manifested in neuropsychiatric disorders.

The contribution of neurotransmitter systems to cortical function likely implicates key species-level differences in the distribution of neurotransmitter fibers and varicosities [Raghanti et al., 2008a-c, 2010], which contribute to differences in the function of assemblages of cortical neurons. Specifically, loss of cholinergic innervation in schizophrenia [Sarter et al., 2005] and ASD [Lam et al., 2006] plays an important role in imbalances in calcium regulation in GABAergic interneurons, particularly CBreactive double bouquet cells, which are major sites of cholinergic inputs [Xiang, 1998]. Given that distinctive clusters of cholinergic fibers were found in human and chimpanzee prefrontal cortex, but not in macaques, fundamental differences in cholinergic innervation likely play a role in cognitive differences [Raghanti et al., 2008c]. This might be related to species-level differences in the organization of the nucleus basalis of Meynert [Raghanti et al., 2011], where cholinergic projections originate. Additionally, differences in serotonergic innervation seem to play a role in cognitive symptomatology in schizophrenia via regulation of oscillatory frequencies [Puig and Gulledge, 2011]. Serotonergic innervation shows some evidence of species-specific patterning, with greater innervation in BAs 9 and 32 in layers V/VI of the human and chimpanzee cortex as compared to macaques [Raghanti et al., 2008b]. Further, differences in dopaminergic innervation in layers III and V/VI among humans and chimpanzees, but not macaques, have been noted. This is of particular interest given that layer VI shows a pattern of decreased dopaminergic innervation in schizophrenic subjects as opposed to controls in BA 9 of the prefrontal cortex [Akil et al., 1999]. Given the involvement of BA 9 in theory of mind tasks [Gallagher and Frith, 2003], variation in neurotransmitter innervation in this area might contribute to inter- and intraspecific variation in mentalizing and social cognition.
Overall, the dysfunction of cortical interneurons in a variety of neurodevelopmental disorders involving deficits in cognition points to their crucial role in supporting normal behavior. Similar to pyramidal neurons, their distribution and morphology bear further investigation in comparative studies. Aberrations of neuronal circuitry contributing to selected deficits in cognition are not restricted to the cortex, however, and we must also consider the functional role that differences in cellular organization may play in subcortical systems supporting behavior.

\section{Beyond the Cortex: Subcortical Systems for Behavioral Control}

Given that subcortical regions share diverse connections with the cerebral cortex, and in light of the phylogenetically dynamic nature of cortical modification [Semendeferi et al., 1998, 2011; Bauernfeind et al., 2013], it should be expected that subcortical structures reflect the changes in the cortical areas with which they share connections [Vilensky et al., 1982]. Our recent analyses of subcortical structures in a broad sample of primate species have shown that some have not kept pace with the expanding cerebral cortex, while others are disproportionately enlarged [Barger et al., 2014]. Whereas two limbic structures, the amygdala and hippocampus, scale larger in humans than would be expected in a hominoid brain of its size, the striatum falls below expected values for total volume among anthropoids. This has interesting implications for the intrinsic organization of these structures, such that relative size of structures may affect cell density and number, and the distribution of different cell types within interconnected regions of the brain.

The amygdala, for example, has been shown to be an important site of reorganization in the evolution of the human brain. Volumetric reorganization of the basolateral division has been marked by differential expansion of discrete nuclei, with the lateral nucleus undergoing disproportionate increases, compared to the basal nucleus, which constitutes the largest subdivision in non-human apes [Barger et al., 2007]. These important volumetric differences are reflected in reorganization at the cellular level: the lateral nucleus in humans shows disproportionate increases in total cellular number when compared to nonhuman apes [Barger et al., 2012]. The shift in emphasis on the lateral nucleus in human evolution, which shares dense connections with the expanded temporal cortex, likely underlies functional differences in emotional pro- 
cessing and social cognition, which helps to account for behavioral differences between humans and our closest living relatives.

The total volume of the hippocampus has not been shown to stand out as differentially enlarged in primate species [Barton, 2000], though its reorganization may underlie key differences. In a small sample of insectivores, rodents and three species of primates, discrete regions of the hippocampus were found to have increased in relative size among primate species [West, 1990]. Therefore, comparative data may show important differences in the distribution of neuronal types and their morphology in the human hippocampus related to its relative increase in size in the human lineage [Barger et al., 2014]. This suggests the potential for modification at the cellular level underlying specializations in learning and memory.

Other subcortical structures have been shown to be sites of reorganization in the human brain. The hominoid thalamus shows differential changes in the size of several of its nuclei, with evidence for modifications at the cellular level. Among motor components of the thalamus, the ventrolateral complex has about 1.5 times as many neurons in humans as are found in the same region in great apes [Armstrong, 1980a]. In its association territories, the human pulvinar nucleus scales larger than expected as compared to other hominoids, and contains nearly twice as many neurons [Armstrong, 1981]. Among the anterior nuclei, most closely associated with limbic connectivity and function, major differences in the relative size of these nuclei have not been found. While a general decrease in cell density is a feature common to most thalamic nuclei in humans, this trend is less pronounced in the anterior nuclei, suggesting differential migration of greater numbers of neurons to limbic-associated territories in the thalamus during development [Armstrong, 1980b, 1986]. Indeed, differences in migration have been noted in regions of the human thalamus, which attract migrating streams of GABAergic interneurons from the telencephalic ganglionic eminence, as compared to the diencephalic origins of these interneurons observed in the development of the macaque brain [Letinic and Rakic, 2001].

Many other subcortical structures of potential interest for human cognitive evolution remain unexplored with respect to how changes in relative size have affected their intrinsic organization at the cellular level. Elements of the basal ganglia are of particular interest, owing to their important role in cognition and behavior. Evidence from cognitive studies has increasingly elucidated the importance of the striatum, particularly the caudate nucleus, as a site of integration for higher-order processes, including action selection, decision making, and reward-based and associative learning [Grahn et al., 2009; Balleine and O'Doherty, 2010], as well as inhibitory control of behavioral responses to stimuli [Aron and Poldrack, 2005]. Recent findings have shown that inhibitory control of behavior varies in species-specific patterns based on ecological and behavioral factors [Shumaker et al., 2001; Amici et al., 2008; Wobber et al., 2010]. The involvement of the caudate in planning and the execution of motor sequences [Graybiel, 1998; van den Heuvel et al., 2003], essential for tool use and production, further hints at its important role in human cognition. Furthermore, insights from Huntington's disease, which causes volumetric loss and cell death in the caudate, have highlighted its functional importance in recursive elements of language, such as syntax and hierarchical structure [Longworth et al., 2005; Teichmann et al., 2006], which are defining features of human language [Pinker and Jackendoff, 2005; Read, 2008].

Analyzing potentially aberrant neuronal distributions in neurodevelopmental disorders that seem to implicate subcortical structures as sites of dysfunction also helps to elucidate mechanisms underlying uniquely human features of cognition. In autism, for example, the amygdala seems to be particularly affected by developmental processes inherent to the disorder. While Schumann and Amaral [2006] found no volumetric differences in the size of the whole amygdala or its main constituent nuclei, substantial reductions in cell numbers in the lateral nucleus were observed, which may contribute to selective deficits in social behavior. Increases in neuron number in the lateral nucleus were found to be a unique feature of the human amygdala as compared to apes, which might underlie functional differences contributing to uniquely human features of emotional regulation and cognition [Barger et al., 2012].

Just as differences in the organization of the cortex have been noted between humans and non-human hominoids, reorganization of subcortical structures, including limbic regions, seems to be an important feature of the human brain's evolution. Targeting disruptions in their intrinsic microstructure in neuropathological conditions, and how this affects cognition and behavior, is of key importance for inferring functional consequences of evolutionary reorganization. Disorders that affect language use, social cognition, object-focused intelligence and other features of human cognition that may be scaled up in our lineage are of particular interest for understanding anatomical specializations and their function. Particularly where the genetic mechanisms guiding variations 
in neural circuitry may be discernable, we can begin to examine the developmental processes underlying functional variations in neural systems.

\section{Modeling Human Evolution through Genetic Disorders: The Case for Williams Syndrome}

A variety of neurodevelopmental disorders affect important features of human cognition and behavior. The processes underlying pathological variation are often complex and involve diverse genetic mechanisms, as is the case in schizophrenia [Eisenberg and Berman, 2010] and ASD [Freitag, 2007], which seem to involve a high rate of de novo mutations [Sebat et al., 2007; Sanders et al., 2012]. Other neurodevelopmental disorders, particularly those with a more well-defined genetic etiology, may provide better models for studying links between neuropathology, function and variation in human evolution. Disorders such as Williams syndrome that are caused by a known deletion can provide a 'living knock-out model' for studying associations between atypical genotypes and neuropathological phenotypes [Bellugi et al., 1999; JärvinenPasley et al., 2008]. Williams syndrome is a rare genetic disorder caused by a hemizygous deletion of about 26-28 genes on chromosome band 7q11.23. This region has undergone a number of sweeps of purifying selection in the hominoid lineage suggesting it is a 'hot spot' for genomic change in recent human evolution [Antonell et al., 2005].

Williams syndrome is characterized by multiple systemic effects, including distinctive facial morphology, slowed growth and cardiac abnormalities [Williams et al., 1961; Beuren et al., 1962], in part related to the deletion of the gene for elastin, which is used as the definitive marker for the disorder. Individuals with Williams syndrome additionally display a relatively predictable and consistent cognitive and behavioral phenotype, including global reductions in total IQ, particularly with respect to visuospatial intelligence [Meyer-Lindenberg et al., 2006]. Curiously, individuals with Williams syndrome have been shown to demonstrate linguistic capacity characterized by elaborated vocabulary and unusually expressive use of phrases [Reilly et al., 2004; Udwin and Yule, 2005], but struggle with elements of syntax, grammatical structure and embedded meaning [Karmiloff-Smith et al., 1997; Brock, 2007]. Among the most salient features of Williams syndrome, affected individuals tend to show an abnormally high drive to engage in social and affiliative behavior, and exhibit an unusual willingness to approach strangers [Doyle et al., 2004; Järvinen-Pasley et al., 2008].
Specific cognitive impairments in Williams syndrome have been linked to a variety of structural and functional abnormalities noted in patients diagnosed with the disorder. Brains of individuals with Williams syndrome tend to be smaller overall than in typically developing individuals [Jernigan and Bellugi, 1990], with notable size reductions found in the parietal lobule [Eckert et al., 2005], occipital gray matter [Reiss et al., 2000], intraparietal sulcus and orbitofrontal cortex [Meyer-Lindenberg et al., 2006]. Functional abnormalities have been demonstrated with respect to primary auditory [Levitin et al., 2003] and visual perception [Atkinson et al., 2007]. Additionally, deficits in object-focused and spatial cognition and memory have implicated the dorsal visual stream [Atkinson et al., 2003] and hippocampal formation [Meyer-Lindenberg et al., 2005a].

To date, histological studies in Williams syndrome have targeted primarily cortical areas. The primary visual cortex in a postmortem sample of Williams syndrome patients showed abnormalities in cell size and packing density [Galaburda and Bellugi, 2000]. Additionally, the primary auditory cortex shows no significant difference in cell density, despite lacking differences in asymmetry in this region as compared to normal controls. A greater proportion of larger neurons in layer II of the primary auditory cortex, as well as enlarged neuronal size in layer IV [Holinger et al., 2005], suggests differences in connectivity with limbic regions that reflect differences in emotional reactivity to sound, particularly music.

Subcortical structures merit further study in Williams syndrome to determine microstructural abnormalities that underlie tradeoffs between cognitive deficits and conserved or enhanced processes that manifest in the disorder. Given structural abnormalities present in the hippocampal formation, and its importance in spatial cognition, cytoarchitectural study of this region is warranted [Meyer-Lindenberg et al., 2005a, 2006]. Additionally, the amygdala has shown decreased reactivity to threatening stimuli and fearful faces in individuals with Williams syndrome as compared to typically developing controls [Meyer-Lindenberg et al., 2005b]. Investigations of cellular distributions and morphology in the amygdala will help to elucidate the limbic correlates of emotional processing differences displayed in Williams syndrome [Doyle et al., 2004; Bellugi et al., 1999].

Evidence from functional imaging studies has also suggested that the striatum may be differentially affected by developmental abnormalities characteristic of the disorder. Hypersociality and increased affiliative drive in Williams syndrome patients represent selected deficits in 
the ability to suppress behavioral responses [Frigerio et al., 2006]. Attention deficit hyperactivity disorder is a frequent comorbid diagnosis in these individuals [Carrasco et al., 2005]. Mobbs et al. [2007] showed slower reaction times among Williams syndrome patients in a go/no-go task as compared with typically developing control participants, and substantially reduced BOLD signal activity in the striatum was observed. Given the role of frontostriatal circuits in controlling behavioral responses, microstructural abnormalities in the striatum, and particularly the caudate [Reiss et al., 2004] may underlie behavioral deficits in response inhibition and the control of behavioral responses.

Features of language use in Williams syndrome further point to a role for the striatum in the disorder's neurogenetic phenotype. Deficits in sentence morphology and syntax [Karmiloff-Smith et al., 1997] indicate difficulty in encoding rules of proper language use and grammatical structure [Clahsen, 1998; Thomas and Karmiloff-Smith, 2005]. Given the role of the striatum in recursive elements and rule encoding in language use and acquisition [Teichmann et al., 2006], these processing abnormalities might be related to differences in striatal microstructure.

Perhaps the best-described feature of individuals with Williams syndrome includes what has been described as hypersociability and the intense drive to engage in social interactions with strangers. Given this exaggerated proclivity to engage in affiliative behavior, as well as heightened reactivity to emotional stimuli, such as music, Dai et al. [2012] expected to find an increase in basal levels of the social neuropeptide oxytocin in adult individuals with Williams syndrome as compared to typically developed control participants. Indeed, individuals with Williams syndrome had higher baseline levels of oxytocin, and these results correlated positively with social approach, and negatively with adaptive social behavior. Given the relationship between oxytocin receptors and dopaminergic input to the nucleus accumbens [Carter, 1998; Insel, 2003; Aragona et al., 2006], differences in dopaminergic innervation in the ventral striatum, as well as the morphology of the nucleus accumbens, hint at a functional role of the subcortical systems in modulating these behavioral features.

Preliminary analysis of pyramidal neurons in Williams syndrome has revealed anomalies in the organization of dendritic trees specific to a particular cortical layer. In layers II/III the neurons displayed aberrations from typical cells across cortical areas as seen in controls [Hrvoj-Mihic et al., 2013], whereas in layers V/VI the neurons displayed more elaborated dendritic branching compared to controls [Chailangkarn et al., 2013]. Inter-

Human Evolutionary Neuroanatomy and Neurodevelopmental Disorders estingly, the deletion that causes Williams syndrome, at the 7q11.23 chromosomal region [Osborne et al., 1996], is duplicated in some cases of ASD [Sanders et al., 2012]. At the same time, the two disorders are characterized by different social, cognitive and verbal phenotypes. A comparison between Williams syndrome and ASD at different levels, encompassing macroanatomical and microstructural changes, cognition and genetic underpinnings of each disorder, can offer an exciting new paradigm for evolutionary analyses encompassing several levels of inquiry across several scientific fields.

\section{Conclusions}

Ecological pressures, including the increased complexity of the social milieu, have driven the development of a highly specialized morphology in primate taxa. Despite the importance of the human brain's anatomical specializations for providing the material substrate to support extraordinary behavioral flexibility, complex cognition, and language as hallmark features of human evolution, relatively little is known about the reorganization of the brain that supports these unique faculties. While studying the evolution of the brain through fossil endocasts offers the only direct evidence of its expansion and potential reorganization, these investigations are limited to examining changes in the size and external gross morphology of its structural features. Targeting indirect evidence through comparative approaches allows for inferences to be made about human brain evolution from a phylogenetic perspective. A variety of noninvasive, nondestructive neuroimaging techniques, including magnetic resonance imaging and diffusion tensor imaging, allow for the comparative study of brain structure in extant taxa, and can provide great insights into structure and the connectivity of structures, respectively.

Changes in the volume and connectivity of brain structures often entail an increase in total neuron number and processing capacity, and evidence at the microstructural level continues to reveal unique patterns of cellular organization, neurotransmitter distribution and development that show that the human brain is not simply an enlarged primate brain. Patterns of reorganization in the human brain remain enigmatic, and the effects that the expanding cerebral cortex has had on cellular distributions in cortical and subcortical regions as a result merit further study. Investigations of hominoid cellular neuroanatomy in comparative perspective have been limited by the practical considerations involved in securing rare brain materials 
from critically endangered great ape taxa. Analyzing potentially aberrant neuronal distributions in neurodevelopmental disorders, in addition to phylogenetic comparative approaches, will help to elucidate functional mechanisms underlying complex cognition. Given the dynamic and rapid changes observed in the region of the human genome deleted in Williams syndrome, and its unusual and consistent behavioral phenotype, understanding the effects of this deletion may further help us to better conceptualize the dynamic interplay of genetic influences and development on uniquely human neurobiology.

\section{Acknowledgements}

We would like to thank Dr. Chet Sherwood and the participants of the 25th annual Karger Workshop in Evolutionary Neuroscience for the opportunity to share diverse, transdisciplinary perspectives with the common goal of understanding and describing the evolution of brain and mind. This paper is dedicated to the memory of Dr. Lisa Stefanacci and Dr. Gary van Hoesen, who continue to inspire ongoing research and scholarship in comparative neuroanatomy from an evolutionary perspective. Support has been provided by the National Institute for Health (P01NICHD033113) and the Wenner Gren Foundation (dissertation fieldwork grant).

\section{References}

Akil M, Pierri JN, Whitehead RE, Edgar CL, Mohila C, Sampson AR, et al. (1999): Laminaspecific alterations in the dopamine innervation of the prefrontal cortex in schizophrenic subject. Am J Psychiatry 156:1580-1589.

Aldridge K (2011): Patterns of differences in brain morphology in humans as compared to extant apes. J Hum Evol 60:94-105.

- Amici F, Aureli F, Call J (2008): Fission-fusion dynamics, behavioral flexibility, and inhibitory control in primates. Curr Biol 18:1415-1419.

-Antonell A, de Luis O, Domingo-Roura X, PérezJurado LA (2005): Evolutionary mechanisms shaping the genomic structure of the Williams-Beuren syndrome chromosomal region at human 7q11.23. Genome Res 15:11791188.

Aragona BJ, Liu Y, Yu YJ, Curtis JT, Detwiler JM, Insel TR, et al (2006): Nucleus accumbens dopamine differentially mediates the formation and maintenance of monogamous pair bonds. Nat Neurosci 9:133-139.

Armstrong DD, Dunn JK, Antalffy B (1998): Decreased dendritic branching in frontal, motor and limbic cortex in Rett syndrome compared with trisomy 21. J Neuropath Exp Neur 57: 1013-1017.

Armstrong E (1980a): A quantitative comparison of the hominoid thalamus. III. A motor substrate - the ventrolateral complex. Am J Phys Anthropol 52:405-419.

-Armstrong E (1980b): A quantitative comparison of the hominoid thalamus. II. Limbic nuclei anterior principalis and lateralis dorsalis. Am J Phys Anthropol 52:43-54.

Armstrong E (1981): A quantitative comparison of the hominoid thalamus. IV. Posterior association nuclei-the pulvinar and lateral posterior nucleus. Am J Phys Anthropol 55:369383.

-Armstrong E (1986): Enlarged limbic structures in the human brain: the anterior thalamus and medial mamillary body. Brain Res 362 : 394-397.
Aron AR, Poldrack RA (2005): The cognitive neuroscience of response inhibition: relevance for genetic research in attention-deficit/hyperactivity disorder. Biol Psychiatry 157:12851292.

Ascoli GA, Alonso-Nanclares L, Anderson SA, Barrionuevo G, Benavides-Piccione R, Burkhalter A, et al (2008): Petilla terminology: nomenclature of features of GABAergic interneurons of the cerebral cortex. Nat Rev Neurosci 9:557-568.

Atkinson J, Anker S, Braddick O, Nokes L, Mason A, Braddick F (2007): Visual and visuospatial development in young children with Williams syndrome. Dev Med Child Neurol 2: 330-337.

Atkinson J, Braddick O, Anker S, Curran W, Andrew R, Wattam-Bell J, et al. (2003): Neurobiological models of visuospatial cognition in children with Williams syndrome: measures of dorsal-stream and frontal function. Dev Neuropsychol 23:139-172.

Balleine BW, O’Doherty JP (2010): Human and rodent homologies in action control: corticostriatal determinants of goal-directed and habitual action. Neuropsychopharmacology 23: 48-69.

Barbas H (1995): Anatomic basis of cognitiveemotional interactions in the primate prefrontal cortex. Neurosci Biobehav R 19:499510.

Barbas H, Henion TH, Dermon CR (1991): Diverse thalamic projections to the prefrontal cortex in the rhesus monkey. J Comp Neurol 313:65-94.

Barbas H, Hilgetag CC (2002): Rules relating connections to cortical structure in primate prefrontal cortex. Neurocomputing 44:301-308

Barger N, Hanson KL, Schenker NM, Teffer K, Semendeferi K (2014): Evidence for evolutionary specialization in human limbic structures. Front Hum Neurosci 8:277.
Barger N, Stefanacci L, Schumann CM, Sherwood CC, Annese J, Allman JM, et al (2012): Neuronal populations in the basolateral nuclei of the amygdala are differentially increased in humans compared with apes: a stereological study. J Comp Neurol 520:3035-3054.

Barger N, Stefanacci L, Semendeferi K (2007): A comparative volumetric analysis of the amygdaloid complex and basolateral division in the human and ape brain. Am J Phys Anthropol 134:392-403.

Barton RA (2000): Primate brain evolution: $\operatorname{cog}$ nitive demands of foraging or of social life?; in Boinski S, Garber P (eds): On the Move: How and Why Animals Travel in Groups. Chicago, University of Chicago Press, 2000, pp 204237.

Barton RA, Harvey PH (2000): Mosaic evolution of brain structure in mammals. Nature 405: 1055-1058.

Barton RA, Venditti C (2013): Human frontal lobes are not relatively large. Proc Natl Acad Sci USA 110:9001-9006.

Bauernfeind AL, de Sousa AA, Avasthi T, Dobson SD, Raghanti MA, Lewandowski AH, et al (2013): A volumetric comparison of the insular cortex and its subregions in primates. $J$ Hum Evol 64:263-279.

Belichenko PV, Oldfors A, Hagberg B, Dahlström A (1994a): Rett syndrome: 3D confocal microscopy of cortical pyramidal dendrites and afferents. Neuroreport 5:1509-1513.

Belichenko PV, Sourander P, Malmgren K, Nordborg C, von Essen C, Rydenhag B, Lindström S, Hedström A, Uvebrant P, Dahlström A (1994b): Dendritic morphology in epileptogenic cortex from TRPE patients, revealed by intracellular Lucifer Yellow microinjection and confocal laser scanning microscopy. Epilepsy Res 18:233-247.

Bellugi U, Lichtenberger L, Mills D, Galaburda A, Korenberg JR (1999): Bridging cognition, the brain and molecular genetics: evidence from Williams syndrome. Trends Neurosci 22: 197-207. 
Benes FM (1991): Deficits in small interneurons in prefrontal and cingulate cortices of schizophrenic and schizoaffective patients. Arch Gen Psychiatry 48:996.

Beuren AJ, Apitz J, Harman D (1962): Supravalvular aortic stenosis in association with mental retardation and a certain facial appearance. Circulation 26:1235-1240.

-Bianchi S, Stimpson CD, Bauernfeind AL, Schapiro SJ, Baze WB, McArthur MJ, Bronson E, Hopkins WD, Semendeferi K, Jacobs B, Hof PR, Sherwood CC, (2012): Dendritic morphology of pyramidal neurons in the chimpanzee neocortex: regional specializations and comparison to humans. Cereb Cortex 23: 2429-2436.

-Bianchi S, Stimpson CD, Duka T, Larsen MD, Janssen WG, Collins Z, Bauernfeind AL, Schapiro SJ, Baze WB, McArthur MJ, Hopkins WD, Wildman DE, Lipovich L, Kuzawa CW, Jacobs B, Hof PR, Sherwood CC (2013): Synaptogenesis and development of pyramidal neuron dendritic morphology in the chimpanzee neocortex resembles humans. Proc Natl Acad Sci USA 110(suppl 2):1039510401.

Bock J, Gruss M, Becker S, Braun K (2005): Experience-induced changes of dendritic spine densities in the prefrontal and sensory cortex: correlation with developmental time windows. Cereb Cortex 15:802-808.

-Brennand KJ, Simone A, Jou J, Gelboin-Burkhart C, Tran N, Sangar S, Li Y, Mu Y, Chen G, Yu D, McCarthy S, Sebat J, Gage FH (2011): Modelling schizophrenia using human induced pluripotent stem cells. Nature 473: 221-225.

Brock J (2007): Language abilities in Williams syndrome: a critical review. Dev Psychopathol 119:97-127.

-Brown SM, Henning S, Wellman CL (2005): Mild, short-term stress alters dendritic morphology in rat medial prefrontal cortex. Cereb Cortex 15:1714-1722.

Brüne M (2005): 'Theory of mind' in schizophrenia: a review of the literature. Schizophr Bull 31:21-42.

Bruner E (2010): Morphological differences in the parietal lobes within the human genus. Curr Anthropol 51:S77-S88.

Bryan GK, Riesen AH (1989): Deprived somatosensory-motor experience in stumptailedmonkey neocortex: dendritic spine density and dendritic branching of layer IIIb pyramidal cells. J Comp Neurol 286:208-217.

- Buard I, Rogers SJ, Hepburn S, Kronberg E, Rojas DC (2013): Altered oscillation patterns and connectivity during picture naming in autism. Front Hum Neurosci 7:742.

Burns JK (2006): Psychosis: a costly by-product of social brain evolution in Homo sapiens. Prog Neuropsychopharmacol Biol Psychiatry 30: 797-814.

Bush EC, Allman JM (2004): The scaling of frontal cortex in primates and carnivores. Proc Natl Acad Sci USA 101:3962-3966.
Buxhoeveden DP, Semendeferi K, Buckwalter J, Schenker N, Switzer R, Courchesne E (2006): Reduced minicolumns in the frontal cortex of patients with autism. Neuropathol Appl Neurobiol 32:483-491.

Byrne RW (2004): The manual skills and cognition that lie behind hominid tool use; in Russon AE, Begun DR (eds): The Evolution of Thought: Evolutionary Origins of Great Ape Intelligence. Cambridge, Cambridge University Press.

Byrne RW, Whiten A (1989): Machiavellian Intelligence: Social Expertise and the Evolution of Intellect in Monkeys, Apes, and Humans. Oxford, Oxford University Press.

Call J, Tomasello M (1995): Use of social information in the problem solving of orangutans (Pongo pygmaeus) and human children (Homo sapiens). J Comp Psychol 109:308320.

Carrasco X, Castillo S, Aravena T, Rothhammer P, Aboitiz F (2005): Williams syndrome: pediatric, neurologic, and cognitive development. Pediatr Neurol 32:166-172.

Carter SC (1998): Neuroendocrine perspectives on social attachment and love. Psychoneuroendocrinology 23:779-818.

Casanova MF, Buxhoeveden DP, Switala AE, Roy E (2002): Minicolumnar pathology in autism. Neurology 58:428-432.

-Casanova MF, van Kooten IAJ, Switala AE, van Engeland H, Heinsen H, Steinbusch HWM, et al (2006): Minicolumnar abnormalities in autism. Acta Neuropathol 112:287-303.

Cerqueira JJ, Taipa R, Uylings HBM, Almeida OFX, Sousa N (2007): Specific configuration of dendritic degeneration in pyramidal neurons of the medial prefrontal cortex induced by differing corticosteroid regimens. Cereb Cortex 17:1998-2006.

Chagnac-Amitai Y, Luhmann HJ, Prince DA (1990): Burst generating and regular spiking layer 5 pyramidal neurons of rat neocortex have different morphological features. J Comp Neurol 296:598-613.

Chailangkarn E, Hrvoj-Mihic B, Stefanacci L, Marchetto C, Yu D, Bardy C, Bellugi U, Gage F, Semendeferi K, Muotri AR (2013): Williams syndrome: a closer look into the dish (abstract). 43rd Annu Meet Soc Neurosci, San Diego.

Chao H-T, Chen H, Samaco RC, Xue M, Chahrour M, Yoo J, et al (2010): Dysfunction in GABA signalling mediates autism-like stereotypies and Rett syndrome phenotypes. Nature 468:263-269.

-Churchill JD, Tharp J, Wellman CL, Sengelaub DR, Garraghty PE (2004): Morphological correlates of injury-induced reorganization in primate somatosensory cortex. BMC Neuroscience 5:43.

Clahsen H (1998): Syntax and morphology in Williams syndrome. Cognition 68:167-198.

Connors BW, Gutnick MJ (1990): Intrinsic firing patterns of diverse neocortical neurons. Trends Neurosci 13:99-104.
Connors BW, Gutnick MJ, Prince DA (1982): Electrophysiological properties of neocortical neurons in vitro. J Neurphysiol 48:13021320.

Cook SC, Wellman CL (2004): Chronic stress alters dendritic morphology in rat medial prefrontal cortex. J Neurobiol 60:236-248.

Courchesne E, Mouton PR, Calhoun ME, Semendeferi K, Ahrens-Barbeau C, Hallet MJ, et al (2011): Neuron number and size in prefrontal cortex of children with autism. JAMA 306:2001-2010.

Cupp CJ, Uemura E (1980): Age-related changes in prefrontal cortex of Macaca mulatta: quantitative analysis of dendritic branching patterns. Exp Neurol 69:143-163.

-Curia G, Papouin T, Séguéla P, Avoli M (2009): Downregulation of tonic GABAergic inhibition in a mouse model of fragile $\mathrm{X}$ syndrome. Cereb Cortex 19:1515-1520.

Crespi B, Summers K, Dorus S (2007): Adaptive evolution of genes underlying schizophrenia. Proc Biol Sci 274:2801-2810.

-Crow TJ (1998): Nuclear schizophrenic symptoms as a window on the relationship between thought and speech. Br J Psychiatry 173:303309.

Crow TJ (2000): Schizophrenia as the price that Homo sapiens pays for language: a resolution of the central paradox in the origin of the species. Brain Res 31:118-129.

Dai L, Carter CS, Ying J, Bellugi U, PournajafiNazarloo H, Korenberg JR (2012): Oxytocin and vasopressin are dysregulated in Williams syndrome, a genetic disorder affecting social behavior. PLoS 7:e38513.

Deacon TW (1997): The Symbolic Species: The Co-Evolution of Language and the Brain. New York, WW Norton \& Company.

DeFelipe J (1997): Types of neurons, synaptic connections and chemical characteristics of cells immunoreactive for calbindin-D28K, parvalbumin and calretinin in the neocortex. J Chem Neuroanat 14:1-19.

-DeFelipe J, Alonso-Nanclares L, Arellano JI (2002): Microstructure of the neocortex: comparative aspects. J Neurocytol 31:299-316.

DeFelipe J, Fariñas I (1992): The pyramidal neuron of the cerebral cortex: morphological and chemical characteristics of the synaptic inputs. Prog Neurobiol 39:563-607.

DeFelipe J, López-Cruz PL, Benavides-Piccione $\mathrm{R}$, Bielza C, Larrañaga $\mathrm{P}$, Anderson S, et al (2013): New insights into the classification and nomenclature of cortical GABAergic interneurons. Nat Rev Neurosci 14:202-216.

Di Virgilio G, Clarke S (1997): Direct interhemispheric visual input to human speech areas. Hum Brain Mapp 5:347-354.

Dinstein I, Pierce K, Eyler L, Solso S, Malach R, Behrmann M, et al. (2011): Disrupted neural synchronization in toddlers with autism. Neuron 70:1218-1225.

Dombrowski SM (2001): Quantitative architecture distinguishes prefrontal cortical systems in the rhesus monkey. Cereb Cortex 11:975988.
Human Evolutionary Neuroanatomy and Neurodevelopmental Disorders
Brain Behav Evol 2014;84:135-155 DOI: 10.1159/000365409 
Doyle TF, Bellugi U, Korenberg JR, Graham J Elston GN, Benavides-Piccione R, Elston A, De(2004): 'Everybody in the world is my friend' hypersociability in young children with Williams syndrome. Am J Med Genet A 124A: 263-273.

Dunbar RIM (1998). The social brain hypothesis. Evol Anthropol 6:178-190.

Eckert MA, Hu D, Eliez S, Bellugi U, Galaburda A, Korenberg J, et al (2005): Evidence for superior parietal impairment in Williams syndrome. Neurology 64:152-153.

- Eisenberg DP, Berman KF (2010): Executive function, neural circuitry, and genetic mechanisms in schizophrenia. Neuropsychopharmacology 35:258-277.

Elston GN (2000): Pyramidal cells of the frontal lobe: all the more spinous to think with. J Neurosci 20:RC95.

Elston GN (2007): Specialization of the neocortical pyramidal cell during primate evolution; in Preuss TM, Kaas JH (eds): The Evolution of Nervous Systems: The Evolution of Primate Nervous Systems. Amsterdam, Elsevier, vol 4, pp 191-242.

-Elston GN, Benavides-Piccione R, DeFelipe J (2001): The pyramidal cell in cognition: a comparative study in human and monkey. J Neurosci 21:RC163.

-Elston GN, Benavides-Piccione R, DeFelipe J (2005a): A study of pyramidal cell structure in the cingulate cortex of the macaque monkey with comparative notes on inferotemporal and primary visual cortex. Cereb Cortex 15: 64-73.

-Elston GN, Benavides-Piccione R, Elston A, DeFelipe J, Manger P (2005b): Specialization in pyramidal cell structure in the cingulate cortex of the Chacma baboon (Papio ursinus): an intracellular injection study of the posterior and anterior cingulate gyrus with comparative notes on the macaque and vervet monkeys. Neurosci Lett 387:130-135.

-Elston GN, Benavides-Piccione R, Elston A, DeFelipe J, Manger P (2005c): Pyramidal cell specialization in the occipitotemporal cortex of the chacma baboon (Papio ursinus). Exp Brain Res 167:496-503.

-Elston GN, Benavides-Piccione R, Elston A, Manger P, DeFelipe J (2005d): Specialization in pyramidal cell structure in the sensory-motor cortex of the chacma baboon (Papio ursinus) with comparative notes on macaque and vervet monkeys. Anat Rec A Discov Mol Cell Evol Biol 286:854-865.

-Elston GN, Benavides-Piccione R, Elston A, Manger P, DeFelipe J (2005e): Regional specialization in pyramidal cell structure in the limbic cortex of the vervet monkey (Cercopithecus pygerythrus): an intracellular injection study of the anterior and posterior cingulate gyrus. Exp Brain Res 167:315-323.

-Elston GN, Benavides-Piccione R, Elston A, Manger P, DeFelipe J (2005f): Pyramidal cell specialization in the occipitotemporal cortex of the vervet monkey. Neuroreport 16:967-970. Felipe J, Manger P (2005g): Specialization in pyramidal cell structure in the sensory-motor cortex of the vervet monkey (Cercopithicus pygerythrus). Neuroscience 134:1057-1068.

-Elston, GN, Benavides-Piccione R, Elston A, Zietsch B, DeFelipe J, Manger P, Casagrande V, Kaas JH (2006): Specializations of the granular prefrontal cortex of primates: implications for cognitive processing. Anat Rec A Discov Mol Cell Evol Biol 288:26-35.

Elston GN, Elston A, Kaas JH, Casagrande V (2005h): Regional specialization in pyramidal cell structure in the visual cortex of the galago: an intracellular injection study of striate and extrastriate areas with comparative notes on New World and Old World monkeys. Brain Behav Evolut 66:10-21.

Elston GN, Rockland KS (2002): The pyramidal cell of the sensorimotor cortex of the macaque monkey: phenotypic variation. Cereb Cortex 12:1071-1078.

Elston GN, Rosa MG (1998): Morphological variation of layer III pyramidal neurones in the occipitotemporal pathway of the macaque monkey visual cortex. Cereb Cortex 8:278294.

-Elston GN, Rosa MG (2000): Pyramidal cells, patches, and cortical columns: a comparative study of infragranular neurons in TEO, TE, and the superior temporal polysensory area of the macaque monkey. J Neurosci 20:RC117.

Falk D, Redmond JC, Guyer J, Conroy C, Recheis W, Weber GW, et al. (2000): Early hominid brain evolution: a new look at old endocasts. J Hum Evol 38:695-717.

-Ferrer I, Roig C, Espino A, Peiro G, Guiu MX (1991): Dementia of frontal lobe type and motor neuron disease: a Golgi study of the frontal cortex. J Neurol Neurosurg Psychiatry 54: 932-934.

-Freitag CM (2007): The genetics of autistic disorders and its clinical relevance: a review of the literature. Mol Psychiatry 12:2-22.

Frigerio E, Burt DM, Gagliardi C, Cioffi G, Martelli S, Perrett DI, et al. (2006): Is everybody always my friend? Perception of approachability in Williams syndrome. Neuropsychologia 44:254-259.

Galaburda AM, Bellugi U (2000): V. Multi-level analysis of cortical neuroanatomy in Williams syndrome. J Cogn Neurosci 12(suppl 1):7488.

Gallagher HL, Frith CD (2003): Functional imaging of 'theory of mind'. Trends Cogn Sci 7: 77-83.

Garey LJ, Ong WY, Patel TS, Kanani M, Davis A, Mortimer AM, Barnes TRE, Hirsch SR (1998): Reduced dendritic spine density on cerebral cortical pyramidal neurons in schizophrenia. J Neurol Neurosurg Psychiatry 65:446-453.

Glantz LA, Lewis DA (2000): Decreased dendritic spine density on prefrontal cortical pyramidal neurons in schizophrenia. Arch Gen Psychiatry $57: 65-73$.
Globus A, Rosenzweig MR, Bennett EL, Diamond MC (1973): Effects of differential experience on dendritic spine counts in rat cerebral cortex. J Comp Physiol Psych 82:175-181.

Globus A, Scheibel AB (1967a): Synaptic loci on parietal cortical neurons: termination of corpus callosum fibers. Science 156:1127-1129.

Globus A, Scheibel AB (1967b): The effect of visual deprivation on cortical neurons: a Golgi study. Exp Neurol 19:331-345.

Grahn JA, Da Cunha C, Packard MG, Parkinson JA, Owen AM (2009): The role of the basal ganglia in learning and memory: neuropsychological studies. Behav Brain Res 99:53-60.

Graybiel AM (1998): The basal ganglia and chunking of action repertoires. Neurobiol Learn Mem 70:119-136.

Green MF, Horan WP (2010): Social cognition in schizophrenia. Curr Dir Psychol Sci 19:243248.

Greenough WT, Juraska JM, Volkmar FR (1979): Maze training effects on dendritic branching in occipital cortex of adult rats. Behav Neural Biol 26:287-297.

Greenough WT, Volkmar FR, Juraska JM (1973): Effects of rearing complexity on dendritic branching in frontolateral and temporal cortex of the rat. Exp Neurol 41:371-378.

Haber SN, Kim KS, Mailly P, Calzavara R (2006): Reward-related cortical inputs define a large striatal region in primates that interface with associative cortical connections, providing a substrate for incentive-based learning. J Neurosci 26:8368-8376.

Hare B (2007): From nonhuman to human mind: what changed and why? Curr Dir Psychol Sci 16:60-64.

- Helmeke C, Ovtscharoff W, Poeggel G, Braun K (2001): Juvenile emotional experience alters synaptic inputs on pyramidal neurons in the anterior cingulate cortex. Cereb Cortex 11: 717-727.

Hendry S, Schwark H, Jones E, Yan J (1987): Numbers and proportions of GABA-immunoreactive neurons in different areas of monkey cerebral cortex. J Neurosci 7:1503-1519.

Hilgetag CC, Barbas H (2006): Role of mechanical factors in the morphology of the primate cerebral cortex. PLoS Comp Biol 2:e22.

-Hinton VJ, Brown WT, Wisniewski K, Rudelli RD (1991): Analysis of neocortex in three males with the fragile X syndrome. Am J Med Gen 41:289-294.

-Holinger DP, Bellugi U, Mills DL, Korenberg JR, Reiss AL, Sherman GF, Galaburda AM (2005): Relative sparing of primary auditory cortex in Williams syndrome. Brain Res 1037:35-42.

Holloway RL (2004): The Human Fossil Record, Brain Endocasts: The Paleoneurological Evidence. Hoboken, John Wiley \& Sons.

Holloway RL, Broadfield DC, Yuan MS (2003): Morphology and histology of chimpanzee primary visual striate cortex indicate that brain reorganization predated brain expansion in early hominid evolution. Anat Rec A Discov Mol Cell Evol Biol 273:594-602. 
Hrvoj-Mihic B, Marchetto MCN, Gage FH, Se- Jernigan TL, Bellugi U (1990): Anomalous brain mendeferi K, Muotri AR (2014): Novel tools, classic techniques: evolutionary studies using primate pluripotent stem cells. Biol Psychiatry 75:929-935.

Hrvoj-Mihic B, Stefanacci L, Hanson KL, Korenberg JR, Muotri AR, Halgren E, Jacobs B, Semendeferi K (2013): Morphology of pyramidal neurons in Williams syndrome (abstract). 43rd Ann Meet Soc Neurosci, San Diego.

Humphrey NK (1976): The social function of intellect; in Bateson PPG, Hinde RA (eds): Growing Points in Ethology. Cambridge, Cambridge University Press, pp 303-317.

-Hutsler JJ, Zhang H (2010): Increased dendritic spine densities on cortical projection neurons in autism spectrum disorders. Brain Res 1309: 83-94.

Huttenlocher PR (1970): Dendritic development and mental defect. Neurology 20:381.

Huttenlocher PR (1974): Dendritic development in cortex of children with mental defects and infantile spasms. Neurology 24:203-210.

- Ieshima A, Takashima S, Takada K, Akamatsu Y, Ohtani K, Ando G (1985): Clinicopathological study in a female infant with $46, \mathrm{XX}, \mathrm{i}(18 \mathrm{q})$ showing mixed features of both trisomy 18 and monosomy 18p. Jpn J Hum Genet 30: 219-226.

Insel TR (2003): Is social attachment an addictive disorder? Physiol Behav 79:351-357.

- Irwin SA, Patel B, Idupulapati M, Harris JB, Crisostomo RA, Larsen BP, Kooy F, Willems PJ, Cras P, Kozlowski PB, Swain RA, Weiler IJ, Greenough WT (2001): Abnormal dendritic spine characteristics in the temporal and visual cortices of patients with fragile $\mathrm{X}$ syndrome: a quantitative examination. Am J Med Genet 98:161-167.

-Jacobs B, Creswell J, Britt JP, Ford KL, Bogen JE Zaidel E (2003): Quantitative analysis of cortical pyramidal neurons after corpus callosotomy. Ann Neurol 54:126-130.

-Jacobs B, Driscoll L, Schall M (1997): Life-span dendritic and spine changes in areas 10 and 18 of human cortex: a quantitative Golgi study. J Comp Neurol 386:661-680.

-Jacobs B, Schall M, Prather M, Kapler E, Driscoll L, Baca S, Jacobs J, Ford K, Wainwright M, Tremi M (2001): Regional and spine variation in human cerebral cortex: a quantitative Golgi study. Cereb Cortex 11:558-571.

-Jacobs B, Schall M, Scheibel AB (1993): A quantitative dendritic analysis of Wernicke's area in humans. II. Gender, hemispheric, and environmental factors. J Comp Neurol 327:97111.

-Järvinen-Pasley A, Bellugi U, Reilly J, Mills DL, Galaburda A, Reiss AL, et al (2008): Defining the social phenotype in Williams syndrome: a model for linking gene, the brain, and behavior. Dev Psychopathol 20:1-35.

-Jay V, Chan FW, Becker LE (1990): Dendritic arborization in the human fetus and infant with the trisomy 18 syndrome. Dev Brain Res 54: 291-294. morphology on magnetic resonance images in Williams syndrome and Down syndrome. Arch Neurol 47:529-533.

Karmiloff-Smith A, Grant J, Berthoud I, Davies M, Howlin P, Udwin O (1997): Language and Williams syndrome: how intact is 'intact'? Child Dev 68:246-262.

Kaufmann WE, Moser HW (2000): Dendritic anomalies in disorders associated with mental retardation. Cereb Cortex 10:981-991.

Khaitovich P, Lockstone HE, Wayland MT, Tsang TM, Jayatilaka SD, Guo AJ, et al (2008): Metabolic changes in schizophrenia and human brain evolution. Genome Biol 9:R124.

Lam KSL, Aman MG, Arnold LE (2006): Neurochemical correlates of autistic disorder: a review of the literature. Res Dev Disabil 27:254289.

Levitin DJ, Menon V, Schmitt JE, Eliez S, White CD, Glover GH, et al (2003): Neural correlates of auditory perception in Williams syndrome: an fMRI study. Neuroimage 18:74-82.

Letinic K, Rakic P (2001): Telencephalic origin of human thalamic GABAergic neurons. Nat Neurosci 4:931-936.

Lewis DA, Curley AA, Glausier JR, Volk DW (2012): Cortical parvalbumin interneurons and cognitive dysfunction in schizophrenia. Trends Neurosci 35:57-67.

- Longworth CE, Keenan SE, Barker RA, MarslenWilson WD, Tyler LK (2005): The basal ganglia and rule-governed language use: evidence from vascular and degenerative conditions. Brain 128:584-596.

-Mainen ZF, Sejnowski TJ (1996): Influence of dendritic structure on firing pattern in model neocortical neurons. Nature 382:363-366.

Marchetto MC, Carromeu C, Acab A. Yu D, Yeo GW, Mu Y, Chen G, Gage FH, Muotri AR (2010): A model for neural development and treatment of Rett syndrome using human induced pluripotent stem cells. Cell 143:527539.

Marín O (2012): Interneuron dysfunction in psychiatric disorders. Nat Rev Neurosci 13:107120.

Marin-Padilla M (1972): Structural abnormalities of the cerebral cortex in human chromosomal aberrations: a Golgi study. Brain Res 44: 625-629.

Marin-Padilla M (1974): Structural organization of the cerebral cortex (motor area) in human chromosomal aberrations. A Golgi study. I. $\mathrm{D}_{1}$ (13-15) trisomy, Patau syndrome. Brain Res 66:375-391.

Marin-Padilla M (1976): Pyramidal cell abnormalities in the motor cortex of a child with Down's syndrome. J Com Neur 167:63-82.

Meyer-Lindenberg A, Hariri AR, Munoz KE, Mervis CB, Mattay VS, Morris CA, et al (2005b): Neural correlates of genetically abnormal social cognition in Williams syndrome. Nat Neurosci 8:991-993.
Meyer-Lindenberg A, Mervis CB, Berman KF (2006): Neural mechanisms in Williams syndrome: a unique window to genetic influences on cognition and behaviour. Nat Rev Neurosci 7:380-393.

Meyer-Lindenberg A, Mervis CB, Sarpal D, Koch P, Steele S, Kohn P, et al (2005a): Functional, structural, and metabolic abnormalities of the hippocampal formation in Williams syndrome. J Clin Invest 115:1888-1895.

- Mobbs D, Eckert MA, Mills D, Korenberg J, Bellugi U, Galaburda AM, et al (2007): Frontostriatal dysfunction during response inhibition in Williams syndrome. Biol Psychiatry 62:256-261.

Mulle J, Penagarikano O, Warren ST (2007): Path to understanding the pathophysiology of Fragile X syndrome. Future Neurol 2:567575

Multani P, Myers RH, Blume HW, Schomer DL, Sotrel A (1994): Neocortical dendritic pathology in human partial epilepsy: a quantitative Golgi study. Epilepsia 35:728-736.

Murmu MS, Salomon S, Biala Y, Weinstock M, Braun K, Bock J (2006): Changes of spine density and dendritic complexity in the prefrontal cortex in offspring of mothers exposed to stress during pregnancy. Eur J Neurosci 24: 1477-1487.

Nieuwenhuys R (1994): The neocortex: an overview of its evolutionary development, structural organization and synaptology. Anat Embryol (Berl) 190:307-337.

- Oblak A, Gibbs TT, Blatt GJ (2009): Decreased GABAA receptors and benzodiazepine binding sites in the anterior cingulate cortex in autism. Autism Res 2:205-219.

Oblak AL, Gibbs TT, Blatt GJ (2010): Decreased GABA(B) receptors in the cingulate cortex and fusiform gyrus in autism. J Neurochem 114:1414-1423.

Oblak AL, Rosene DL, Kemper TL, Bauman ML Blatt GJ (2011): Altered posterior cingulate cortical cyctoarchitecture, but normal density of neurons and interneurons in the posterior cingulate cortex and fusiform gyrus in autism. Autism Res 4:200-211.

- Orekhova EV, Stroganova TA, Nygren G, Tsetlin MM, Posikera IN, Gillberg C, et al (2007): Excess of high frequency electroencephalogram oscillations in boys with autism. Biol Psychiatry 62:1022-1029.

Osborne LR, Martindale D, Scherer SW, Shi XM Huizenga J, Heng HH, Tsui LC (1996): Identification of genes from a $500-\mathrm{kb}$ region at $7 \mathrm{q} 11.23$ that is commonly deleted in Williams syndrome patients. Genomics 36:328-336.

Passingham RE, Smaers JB (2014): Is the prefrontal cortex especially enlarged in the human brain? Allometric relations and remapping factors. Brain Behav Evol 84:156-166.

Petanjek Z, Judas M, Kostovic I, Uylings HBM (2008): Lifespan alterations of basal dendritic trees of pyramidal neurons in the human prefrontal cortex: a layer-specific pattern. Cereb Cortex 18:915-929. 
Petanjek Z, Judas M, Simic G, Rasina MR, Uylings HBM, Rakic P, Kostovic I (2011): Extraordinary neoteny of synaptic spines in the human prefrontal cortex. Proc Natl Acad Sci USA $108 ; 13281-13286$.

Pinker S, Jackendoff R (2005): The faculty of language: what's special about it? Cognition 95: 201-236.

-Porter JT, Johnson CK, Agmon A (2001): Diverse types of interneurons generate thalamusevoked feedforward inhibition in the mouse barrel cortex. J Neurosci 21:2699-2710.

Povinelli DJ, Eddy TJ (1996): What young chimpanzees know about seeing. Soc Res Child Dev 61:1-152.

Puig MV, Gulledge AT (2011): Serotonin and prefrontal cortex function: neurons, networks, and circuits. Mol Neurobiol 44:449-464.

- Purpura DP (1974): Dendritic spine 'dysgenesis' and mental retardation. Science 186:11261128.

Purpura DP, Bodick N, Suzuki K, Rapin I, Wurzelmann S (1982): Microtubule disarray in cortical dendrites and neurobehavioral failure. I. Golgi and electron microscopic studies. Dev Brain Res 5:287-297.

-Raghanti MA, Simic G, Watson S, Stimpson CD, Hof PR, Sherwood CC (2011): Comparative analysis of the nucleus basalis of Meynert among primates. Neuroscience 184:1-15.

Raghanti MA, Spocter MA, Butti C, Hof PR, Sherwood CC (2010): A comparative perspective on minicolumns and inhibitory GABAergic interneurons in the neocortex. Front Neuroanat 4:3.

- Raghanti MA, Stimpson CD, Marcinkiewicz JL, Erwin JM, Hof PR, Sherwood CC (2008a): Cortical dopaminergic innervation among humans, chimpanzees, and macaque monkeys: a comparative study. Neuroscience 155: 203-220.

Raghanti MA, Stimpson CD, Marcinkiewicz JL, Erwin JM, Hof PR, Sherwood CC (2008b): Differences in cortical serotonergic innervation among humans, chimpanzees, and macaque monkeys: a comparative study. Cereb Cortex 18:584-597.

Raghanti MA, Stimpson CD, Marcinkiewicz JL, Erwin JM, Hof PR, Sherwood CC (2008c): Cholinergic innervation of the frontal cortex: differences among humans, chimpanzees, and macaque monkeys. J Comp Neurol 506: 409-424.

Rakic P, Kornack DR (2001): Neocortical expansion and elaboration during primate evolution: a view from neuroembryology; in Falk D, Gibson KR (eds): Evolutionary Anatomy of the Primate Cerebral Cortex. Cambridge, Cambridge University Press, pp 30-56.

Read DW (2008): Working memory: a cognitive limit to non-human primate recursive thinking prior to hominid evolution. Evol Psychol 6:676-714.

-Reilly J, Losh M, Bellugi U, Wulfeck B (2004): 'Frog, where are you?' Narratives in children with specific language impairment, early focal brain injury, and Williams syndrome. Brain Lang 88:229-247.
Reiss AL, Eliez S, Schmitt JE, Straus E, Lai Z, Jones W, et al (2000): IV. Neuroanatomy of Williams syndrome: a high-resolution MRI study. J Cogn Neurosci 12:65-73.

-Reiss AL, Eckert MA, Rose FE, Karchemskiy A, Kesler S, Chang M, et al (2004): An experiment of nature: brain anatomy parallels cognition and behavior in Williams syndrome. J Neurosci 24:5009-5015.

Rilling JK, Glasser MF, Jbabdi S, Andersson J, Preuss TM (2011): Continuity, divergence, and the evolution of brain language pathways. Front Evol Neurosci 3:11.

Rilling JK, Glasser MF, Preuss TM, Ma X, Zhao T, $\mathrm{Hu} X$, et al (2008): The evolution of the arcuate fasciculus revealed with comparative DTI. Nat Neurosci 11:426-428.

Rilling JK, Insel TR (1999): The primate neocortex in comparative perspective using magnetic resonance imaging. J Hum Evol 37:191223.

Rilling JK, Seligman RA (2002): A quantitative morphometric comparative analysis of the primate temporal lobe. J Hum Evol 42:505533.

Rubenstein JLR, Merzenich MM (2003): Model of autism: increased ratio of excitation/inhibition in key neural systems. Genes Brain Behav 2:255-267.

Rudelli RD, Brown WT, Wisniewski K, Jenkins EC, Laure-Kamionowska M, Connell F, Wisniewski HM (1985): Adult fragile X syndrome. Acta Neuropathol 67:289-295.

-Sanders SJ, Murtha MT, Gupta AR, Murdoch JD, Raubeson MJ, Willsey AJ, et al (2012): De novo mutations revealed by whole-exome sequencing are strongly associated with autism. Nature 485:237-241.

-Sarter M, Nelson CL, Bruno JP (2005): Cortical cholinergic transmission and cortical information processing in schizophrenia. Schizophr Bull 31:117-138.

-Schenker NM, Desgouttes AM, Semendeferi K (2005): Neural connectivity and cortical substrates of cognition in hominoids. J Hum 49: 547-569.

-Schlaug G, Armstrong E, Schleichner A, Zilles K (1993): Layer V pyramidal cells in the adult human cingulate cortex. Anat Embryol 187: 515-522.

Schumann CM, Amaral DG (2005): Stereological estimation of the number of neurons in the human amygdaloid complex. J Comp Neurol 491:320-329.

- Sebat J, Lakshmi B, Malhotra D, Troge J, LeseMartin C, Walsh T, et al (2007): Strong association of de novo copy number mutations with autism. Science 316:445-449.

Semendeferi K, Armstrong E, Schleicher A, Zilles K, van Hoesen GW (1998): Limbic frontal cortex in hominoids: a comparative study of area 13. Am J Phys Anthropol 106: 129-155

Semendeferi K, Damasio H (2000): The brain and its main anatomical subdivisions in living hominoids using magnetic resonance imaging. J Hum Evol 38:317-332.
Semendeferi K, Lu A, Schenker N, Damasio H (2002): Humans and great apes share a large frontal cortex. Nat Neurosci 5:272-276.

-Semendeferi K, Schleicher A, Zilles K, Armstrong E, van Hoesen GW (2001): Prefrontal cortex in humans and apes: a comparative study of area 10. Am J Phys Anthropol 114:224-241.

- Semendeferi K, Teffer K, Buxhoeveden DP, Park MS, Bludau SK, Amunts K, Travis K, Buckwalter J (2011): Spatial organization of neurons in the prefrontal cortex sets humans apart from great apes. Cereb Cortex 21:14851497.

-Sherwood CC, Holloway RL, Semendeferi K, Hof PR (2005): Is prefrontal white matter enlargement a human evolutionary specialization? Nat Neurosci 8:537-538.

-Sherwood CC, Raghanti MA, Stimpson CD, Spocter MA, Uddin M, Boddy AM, et al (2010): Inhibitory interneurons of the human prefrontal cortex display conserved evolution of the phenotype and related genes. Proc Biol Sci 277:1011-1020.

-Sherwood CC, Subiaul F, Zawidzki TW (2008): A natural history of the human mind: tracing evolutionary changes in brain and cognition. J Anat 212:426-454

- Shumaker RW, Palkovich AM, Beck BB, Guagnano GA, Morowitz H (2001): Spontaneous use of magnitude discrimination and ordination by the orangutan (Pongo pygmaeus). J Comp Psychol 115:385-391.

-Smaers JB (2013): How humans stand out in frontal lobe scaling. Proc Natl Acad Sci USA 110:E3682.

-Smaers JB, Schleicher A, Zilles K, Vinicius L (2010): Frontal white matter volume is associated with brain enlargement and higher structural connectivity in anthropoid primates. PLoS One 5:e9123.

- Spocter MA, Hopkins WD, Barks SK, Bianchi S, Hehmeyer AE, Anderson SM, et al (2012): Neuropil distribution in the cerebral cortex differs between humans and chimpanzees. J Comp Neurol 520:2917-2929.

-Spruston N (2008): Pyramidal neurons: dendritic structure and synaptic integration. Nat Rev Neurosci 9:206-221.

-Strier KB (2006): Behavioral flexibility in primates: causes and consequences. Inter J Primatol 27:643-645

Subiaul F (2007): The imitation faculty in monkeys: evaluating its features, distribution and evolution. J Anthropol Sci 85:35-62.

- Suetsugu M, Mehraein P (1980): Spine distribution along the apical dendrites of the pyramidal neurons in Down's syndrome. Acta Neuropathol 50:207-210

Takashima S, Becker LE, Armstrong DL, Chan F (1981): Abnormal neuronal development in the visual cortex of the human fetus and infant with Down's syndrome: a quantitative and qualitative Golgi study. Bran Res 225:121.

Hanson/Hrvoj-Mihic/Semendeferi 
Teffer K, Buxhoeveden DP, Stimpson CD, Fobbs AJ, Schapiro SJ, Baze WB, et al (2013): Developmental changes in the spatial organization of neurons in the neocortex of humans and common chimpanzees. J Comp Neurol 521: 4249-4259.

- Teichmann M, Dupoux E, Kouider S, BachoudLévi AC (2006): The role of the striatum in processing language rules: evidence from word perception in Huntington's disease. J Cogn Neurosci 18:1555-1569.

Thomas MSC, Karmiloff-Smith A (2005): Modeling language acquisition in atypical phenotypes. 110:647-682.

Tomasello M, Call J, Gluckman A (1997): Comprehension of novel communicative signs by apes and human children. Child Dev 68: 1067-1080.

Udwin O, Yule W (2005): Expressive language of children with Williams syndrome. Am J Med Genet 37:108-114.

- Uylings HBM, Kuypers K, Diamond MC, Veltman WAM (1978): Effects of differential environments on plasticity of dendrites of cortical pyramidal neurons in adult rats. Exp Neurol 62:658-677.

-Valverde F (1967): Apical dendritic spines of the visual cortex and light deprivation in mouse. Exp Brain Res 3:337-352.

van den Heuvel OA, Groenewegen HJ, Barkhof F, Lazeron RH, van Dyck R, Veltman DJ (2003): Frontostriatal system in planning complexity: a parametric functional magnetic resonance version of the Tower of London task. Neuroimage 18:367-374. van Essen DC (1997): A tension-based theory of morphogenesis and compact wiring in the central nervous system. Nature 385:313-318.

- Vaquero J, Oya S, Cabezudo JM, Bravo G (1982). Morphological study of human epileptic dendrites. Neurosurgery 10:720-724.

Vaughan DW, Cahill CJ (1984): Long term effects of callosal lesions in the auditory cortex of rats of different ages. Neurobiol Aging 5:175-182.

Vilensky JA, van Hoesen GW, Damasio AR (1982): The limbic system and human evolution. J Hum Evol 11:447-460.

Volkmar FR, Greenough WT (1972): Rearing complexity affects branching of dendrites in the visual cortex of the rat. Science 176:14451447.

Vuksic M, Petanjek Z, Rasin MR, Kostovic I (2002): Perinatal growth of prefrontal layer III pyramids in Down syndrome. Pediatr Neurol 27:36-38.

-West MJ (1990): Understanding the brain through the hippocampus the hippocampal region as a model for studying brain structure and function. Prog Brain Res 83:466-473.

Whiten A, van Schaik CP (2007): The evolution of animal 'cultures' and social intelligence. Phil Trans Royal Soc B 362:603-620.

-Williams JCP, Barratt-Boyd BG, Lowe JB (1961): Supravalvular aortic stenosis. Circulation 24: 1311-1318.

Williams RS, Hauser SL, Purpura DP, deLong R, Swisher CN (1980): Autism and mental retardation: neuropathologic studies performed in four retarded persons with autistic behavior. Arch Neurol 37:749-753.
Williams ZM, Eskandar EN (2006): Selective enhancement of associative learning by microstimulation of the anterior caudate. Nature Neurosci 9:562-568.

Wisniewski KE, Segan SM, Miezejeski CM, Sersen EA, Rudelli RD (1991): The Fra(X) syndrome: neurological, electrophysiological, and neuropathological abnormalities. Am J Med Genet 38:476-480.

Wobber V, Wrangham R, Hare B (2010): Bonobos exhibit delayed development of social behavior and cognition relative to chimpanzees. Curr Biol 20:226-230.

Wonders CP, Anderson SA (2006): The origin and specification of cortical interneurons. Nat Rev Neurosci 7:687-696.

Xiang Z (1998): Cholinergic switching within neocortical inhibitory networks. Science 281: 985-988.

- Yizhar O, Fenno LE, Prigge M, Schneider F, Davidson TJ, O'Shea DJ, et al (2011): Neocortical excitation/inhibition balance in information processing and social dysfunction. Nature 477:171-178.

Zeba M, Jovanov-Milosevic N, Petanjek Z (2008): Quantitative analysis of basal dendritic trees of layer IIIc pyramidal neurons in different areas of adult human frontal cortex. Coll Antropol 32:161-169.

Zikopoulos B, Barbas H (2013): Altered neural connectivity in excitatory and inhibitory cortical circuits in autism. Front Hum Neurosci 7:609
Human Evolutionary Neuroanatomy and Neurodevelopmental Disorders
Brain Behav Evol 2014;84:135-155 DOI: $10.1159 / 000365409$ 